\title{
Aerosol optical properties at Lampedusa (Central Mediterranean). 1. Influence of transport and identification of different aerosol types
}

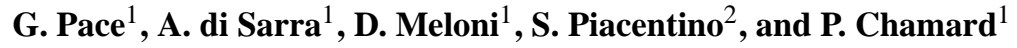 \\ ${ }^{1}$ ENEA, Climate Laboratory, Roma, Italy \\ ${ }^{2}$ ENEA, Climate Laboratory, Lampedusa, Italy
}

Received: 8 November 2004 - Published in Atmos. Chem. Phys. Discuss.: 14 July 2005

Revised: 7 November 2005 - Accepted: 6 December 2005 - Published: 2 March 2006

\begin{abstract}
Aerosol optical depth and Ångström exponent were obtained from multi filter rotating shadowband radiometer (MFRSR) observations carried out at the island of Lampedusa, in the Central Mediterranean, in the period July 2001-September 2003. The average aerosol optical depth at $495.7 \mathrm{~nm}, \tau$, is $0.24 \pm 0.14$; the average Ångström exponent, $\alpha$, is $0.86 \pm 0.63$. The observed values of $\tau$ range from 0.03 to 1.13 , and the values of $\alpha$ vary from -0.32 to 2.05 , indicating a large variability in aerosol content and size. In cloudfree conditions, $36 \%$ of the airmasses come from Africa, 25\% from Central-Eastern Europe, and 19\% from Western France, Spain and the North Atlantic. In summer, $42 \%$ of the airmasses is of African origin. In almost all cases African aerosols display high values of $\tau$ and low values of $\alpha$, typical of Saharan dust (average values of $\tau$ and $\alpha$ are 0.36 and 0.42 , respectively). Particles originating from CentralEastern Europe show relatively large average values of $\tau$ and $\alpha$ (0.23 and 1.5, respectively), while particles from Western France, Spain and the North Atlantic show the lowest average values of $\tau$ (0.15), and relatively small values of $\alpha$ (0.92). Intermediate values of $\alpha$ are often connected with relatively fast changes of the airmass originating sector, suggesting the contemporary presence of different types of particles in the air column. Clean marine conditions are rare at Lampedusa, and are generally associated with subsidence of the airmasses reaching the island. Average values of $\tau$ and $\alpha$ for clean marine conditions are 0.11 and 0.86 , respectively. The largest values of $\alpha$ (about 2) were observed in August 2003, when large scale forest fires in Southern Europe produced consistent amounts of fine combustion particles, that were transported to the Central Mediterranean by a persistent high pressure system over Central Europe. Smoke particles in some cases mix with desert dust, producing intermediate values of $\alpha$. The seasonal distribution of the meteorological
\end{abstract}

Correspondence to: G. Pace

(giandomenico.pace@casaccia.enea.it) patterns over the Mediterranean, the efficiency of the aerosol production mechanisms, and the variability of the particles' residence time produce a distinct seasonal cycle of aerosol optical depths and Ångström exponent values. Particles originating from all sectors show a summer maximum in aerosol optical depth. The summer increase in optical depth for European aerosols is linked with an increment in the values of $\alpha$, that indicates an enhancement in the number of fine particles. The summer maximum of $\tau$ for African particles is associated with a weak reduction in the Ångström exponent, suggesting an increase in the total number of particles and a relatively more intense transport of large particles. The observations were classified according to the aerosol optical properties, and two main classes have been identified: desert dust and biomass burning/urban-industrial aerosols. Values of $\tau$ and $\alpha$ averaged over the whole observing period are 0.37 and 0.15 for desert dust, and 0.27 and 1.77 for urbanindustrial/biomass burning aerosols.

\section{Introduction}

The Mediterranean sea, the largest enclosed basin of the Earth, is a region characterized by positive average net radiation flux (the amount of incoming solar radiation exceeds the infrared emission) surrounded by areas characterized by negative average net fluxes (Bolle, 2003). The continents surrounding the Mediterranean basin have different surface characteristics, and a complex orography. The radiative equilibrium of the basin is thus controlled by a large number of factors, resulting from the mutual influence of the ocean and the continents. Aerosols play an important role: they attenuate the solar radiation (e.g. Markowicz et al., 2002; di Sarra et al., 2003), modify its vertical distribution (e.g. Meloni et al., 2003a, b), affect the infrared balance, and, indirectly, influence the cloud structure and properties (e.g. Levin et al., 1996). Due to the variety of the regions around the basin,

Published by Copernicus GmbH on behalf of the European Geosciences Union. 
different classes of particles can be found in the Mediterranean atmosphere: desert dust, originated from the Sahara desert and from arid regions in the Iberian Peninsula; polluted particles, produced mainly in urban and industrial areas of Continental and Eastern Europe; marine aerosol, continuously formed over the Mediterranean itself or transported from the North Atlantic; and biomass burning particles, often produced in forest fires, mainly during the summer. Moreover, the aerosol properties and the atmospheric chemical composition are influenced by long-range transport (see e.g. Lelieveld et al., 2002).

The two main quantities describing how aerosols influence the radiative balance are the aerosol optical depth, which is an intensive property related to the amount of particles, and the single scattering albedo, which is an extensive property related to the capability to absorb radiation. Various aerosol types display different microphysical and optical properties. Optical depth, composition, size distribution, shape (consequently single scattering albedo, phase function and asymmetry factor), and vertical distribution vary largely in the Mediterranean, thus affecting the radiative balance in different ways. For example, it has been shown that the radiative forcing efficiency (i.e., radiative forcing per unit aerosol optical depth) produced by desert dust in the visible spectral range may differ by a factor of 2 at the surface, and by a factor of 3 at the top of the atmosphere (Meloni et al., 2004), depending on the aerosol source region. Different aerosol types produce negative or positive forcings at top of the atmosphere over the Mediterranean basin (Horvath et al., 2002; Meloni et al., 2003a). Thus, the determination of the aerosol properties is crucial to understand their influence on radiation and climate.

Measurements of aerosol properties over the Mediterranean have been conducted since the 1980s (see the extensive survey by Smirnov et al., 2002), but most of them were occasional, and lasted only for short periods. Later measurements covered longer time periods (Cachorro et al., 2000; Formenti et al., 2001; Sabbah et al., 2001; Tanré et al., 2001; Gerasopoulos et al., 2003; Israelevich et al., 2003; Esposito et al., 2004); most of these studies are based on observations carried out in the coastal regions of the Mediterranean. Analyses based on satellite observations were also carried out to identify the transport of Saharan dust (e.g. Dulac et al., 1992; Moulin et al., 1998; Israelevich et al., 2002; Jamet et al., 2004). Systematic measurements of the aerosol distribution and properties are particularly useful in the open Mediterranean sea, because of the very few measurement sites.

Measurements of aerosol optical depth at several wavelengths were performed in the Central Mediterranean basin. These observations are used in this study combined with airmass trajectories to identify different classes of particles, and to determine their mean optical properties. In a companion paper by Meloni et al. (2005) the collected observations are used to derive estimates of the aerosol single scattering albedo.
The measurements were carried out at the Station for Climate Observations, maintained by ENEA (the national Agency for New Technologies, Energy, and Environment of Italy) at Lampedusa $\left(35.5^{\circ} \mathrm{N}, 12.6^{\circ} \mathrm{E}\right)$. Lampedusa is a small island far from continents, and the local aerosol production is limited. Thus, the aerosol properties depend essentially on long-range transport, and on the formation of marine particles in the Mediterranean. At the Station for Climate Observations, which is located on a $45 \mathrm{~m}$ high plateau on the North-Eastern coast of Lampedusa, continuous observations of greenhouse gases concentration (Chamard et al., 2003), aerosol properties, total ozone, ultraviolet irradiance (di Sarra et al., 2002; Meloni et al., 2004), and other climatic parameters are carried out.

\section{Instrumentation and data retrieval}

This study is based on measurements obtained with a multi filter rotating shadow band radiometer (MFRSR) (Harrison et al., 1994) at Lampedusa during 2001, 2002, and 2003. The MFRSR measures global and diffuse irradiances at six 10 -nm wide channels, centred respectively at 415.6, 495.7, 614.6, 672.6, 868.7 and $939.6 \mathrm{~nm}$, and at one broadband channel $(300-1100 \mathrm{~nm})$. Measurements of global and diffuse radiation are performed every $15 \mathrm{~s}$; data are averaged over longer time intervals, and stored for the analysis. The averaging interval was changed during the measurement period: it was $10 \mathrm{~min}$ from July 2001 to May 2002, and $1 \mathrm{~min}$ afterwards. The direct irradiance is calculated as the difference between global and diffuse irradiances, and is used to derive the aerosol optical depth of all the narrowband channels with the exception of the $939.6 \mathrm{~nm}$ channel, that is strongly influenced by the column water vapour amount. The LambertBeer law is applied to calculate the optical depth; the instrumental extraterrestrial constants are determined by means of Langley plots. The Langley method is to be used with caution at low altitude, because of the possible bias produced by aerosol optical depth variations. The algorithm developed by Harrison and Michalsky (1994) is used to derive the instrumental extraterrestrial constant. In the considered period (July 2001-September 2003), a relatively large number of extraterrestrial constant determinations (65 at $415.6 \mathrm{~nm}$, and 169 at $868.7 \mathrm{~nm}$ ) are averaged to obtain reliable estimates, taking advantage of the high frequency of cloud-free conditions and, consequently, of available half-days suitable for Langley regression. First, the constants determined in the half days characterized by small values of $\tau$ are selected. They are then reduced to the mean Sun-Earth distance and averaged. Averages are calculated over the whole measurement period and over shorter time intervals to verify the instrumental stability. The constants calculated over 6-month periods differ by less than $\pm 4 \%$ at $415.6 \mathrm{~nm}$, and by less $\pm 2 \%$ at the other channels. The instrumental characteristics remain thus reasonably constant throughout the 
observing period; these variations are taken into account by using yearly averages of the extraterrestrial constant. The standard deviation of the average extraterrestrial constant is always $<2.8 \%$ at $415.6 \mathrm{~nm}$, and $<2 \%$ at the other channels, implying an absolute error on $\tau$ due to the uncertainty on the constant $<0.02$ (di Sarra et al., 2002). Systematic errors on $\tau$ due to erroneous values of the extraterrestrial constant are believed to remain within the estimated uncertainties. The aerosol optical depth $\tau$ at each wavelength $\lambda$ is calculated by subtracting Rayleigh scattering and ozone absorption (only for the channels at 495.7, 614.6, and $672.6 \mathrm{~nm}$ ) contributions from the total atmospheric optical depth. Daily mean values of atmospheric pressure and total ozone are used to derive Rayleigh and ozone optical depths ( $\tau_{\text {Ray }}$ and $\tau_{\mathrm{O} 3}$, respectively). The ozone optical depth is calculated by using the absorption cross section at $223 \mathrm{~K}$ (Bogumil et al., 2003) and the total ozone amount routinely measured at Lampedusa with a Brewer spectroradiometer. When Brewer data are not available, observations from the Earth Probe Total Ozone Mapping Sensor, TOMS, version 8 algorithm, are used (http://toms.gsfc.nasa.gov). The Rayleigh optical depth is calculated following Hansen and Travis (1974) and the daily average pressure measured at Lampedusa. When the measured pressure is not available, a value of $1013 \mathrm{mbar}$ is assumed. For this study, only cloud-free periods are selected, thus limiting the amount of available data during winter and autumn. The selection of cloud-free periods is based on the visual inspection of the irradiances (global and diffuse) measured by the broadband channel of the MFRSR. The selection method has been verified by comparing the results with visual sky observations in specific periods, and with wide angle sky photographs acquired with a total sky imager in July-August 2003.

In a companion paper (Meloni et al., 2005), radiative transfer calculations are performed at fixed values of the solar zenith angle to estimate the aerosol single scattering albedo. To maintain a uniform dataset, aerosol optical depth at fixed solar zenith angles are used also in this analysis. Averages of $\tau$ are calculated at fixed solar zenith angle, $\theta=20^{\circ}, 30^{\circ}$, $40^{\circ}, 50^{\circ}$, and $60^{\circ}$, over a $\pm 2.5^{\circ}$ interval around the selected $\theta$. The $\pm 2.5^{\circ}$ solar zenith angle interval is chosen taking into account the measurement time resolution throughout the observation period. The uncertainty $\Delta \tau(\lambda)$ on the average value of $\tau$ is calculated as

$\Delta \tau(\lambda)=\sqrt{\left(\Delta \tau_{\Delta \theta}(\lambda)\right)^{2}+\left(\Delta \tau_{\text {Ray }, \Delta \mathrm{P}(\text { Daily })}(\lambda)\right)^{2}+\left(\Delta \tau_{\mathrm{O}_{3} \text { (Daily) }}(\lambda)\right)^{2}}$,

where $\Delta \tau_{\Delta \theta}$ is the standard deviation of $\tau$ in the $\pm 2.5^{\circ}$ solar zenith angle interval, $\Delta \tau_{\text {Ray }}$ is the daily standard deviation of $\tau_{\text {Ray }}$ resulting from the daily variability of atmospheric pressure, and $\Delta \tau_{\mathrm{O} 3}$ is the daily standard deviation of $\tau_{\mathrm{O} 3}$ due to changes of total ozone. When a single measurements of $\tau$ is available in the $\pm 2.5^{\circ}$ solar zenith angle interval (few cases in 2001), the standard deviation of the average is substituted by 2 times the uncertainty of the single measurement of $\tau$, calculated with the error propagation.

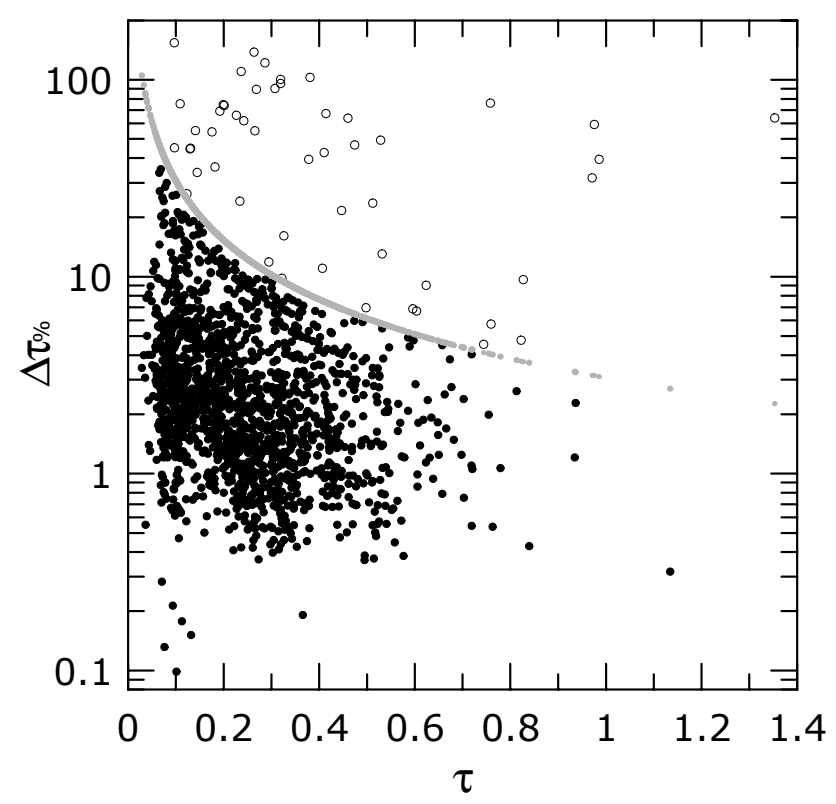

Fig. 1. Behaviour of the percent error, $\Delta \tau_{\%}$, versus the aerosol optical depth at $495.7 \mathrm{~nm}, \tau$. Grey dots are the empirical threshold used to discriminate residual points with large variability; full and open black circles are the selected and excluded measurements respectively.

When Brewer ozone measurements are not available, a $2 \%$ uncertainty on the TOMS total ozone is assumed. Similarly, when the local pressure measurements are missing, an uncertainty of 20 mbar (corresponding to the observed maximum annual distance from the mean value) is used. In the following analyses we discard periods characterized by a large variability of $\tau$ due to large and rapid changes of the aerosol distribution or to residual contamination by clouds. To this aim, we remove all the data with a percent error on $\tau, \Delta \tau \%$, larger than the following empirical threshold $\Delta \tau \%{ }_{M}$ :

$\Delta \tau \%_{M}=100 \times \sqrt{(0.03)^{2}+\left(0.04 * \tau_{\mathrm{Ray}, P_{0}}\right)^{2}+\left(0.25 * \tau_{<03>}\right)^{2}} / \tau$,

where 0.03 is an empirical threshold of the variability of $\tau$; the other two terms on the right identify thresholds of the daily variability of Rayleigh and ozone optical depth. $\tau_{\text {Ray }, P 0}$ is the Rayleigh optical depth calculated with a pressure of 1013 mbar, and $\tau_{<03>}$ is the ozone optical depth with a total ozone amount of $312 \mathrm{DU}$ (the annual mean total ozone at Lampedusa). The behaviour of $\Delta \tau \%$ and $\Delta \tau \% M$ as a function of $\tau$ is shown in Fig. 1. All the data above the limiting threshold are discarded. It is worth noting that averaging around fixed values of $\theta$ implies considering different time intervals during the year; in winter long time intervals, up to $150 \mathrm{~min}$, need to be used. Intervals of time shorter than 6 , between 6 and 36, and longer than 36 min constitute, respectively, 10, 84 and $6 \%$ of the dataset. The Ångström exponent, $\alpha$, is the negative slope of $\tau$ versus wavelength in logarithmic 


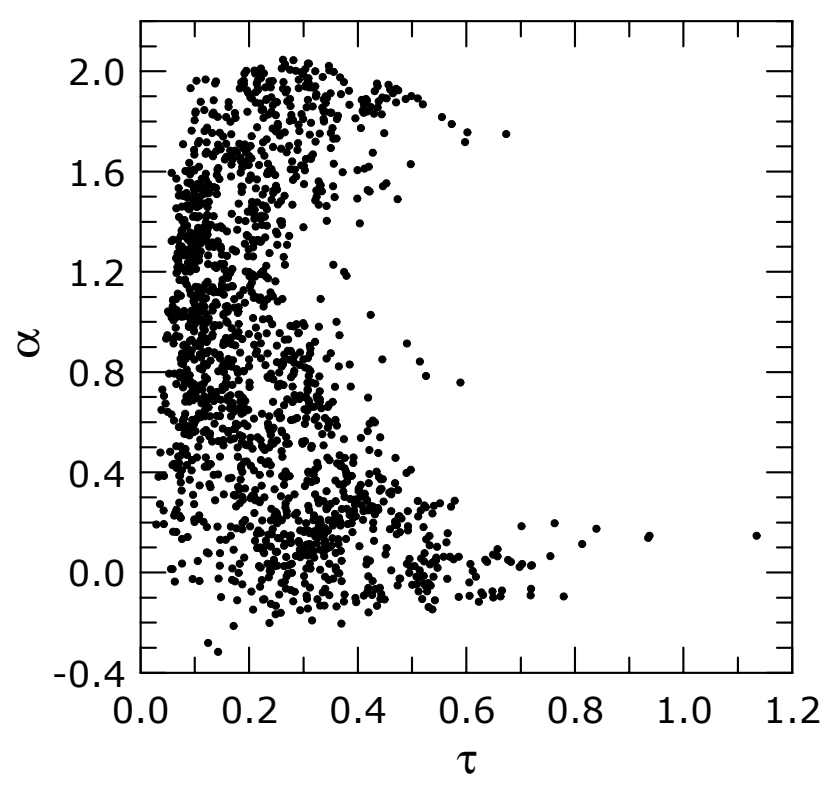

Fig. 2. Behaviour of the Ångström exponent, $\alpha$, as a function of the aerosol optical depth at $495.7 \mathrm{~nm}, \tau$, for cloud-free conditions during July 2001-September 2003.

scale. It is calculated from the values of the aerosol optical depth at 415.6 and $868.7 \mathrm{~nm}$ with the following expression:

$\alpha=-\frac{\ln \left(\tau_{415.6} / \tau_{868.7}\right)}{\ln (415.6 / 868.7)}$.

The uncertainty on $\alpha$ is derived from the error propagation formula.

\section{Analysis}

\subsection{Optical properties}

Figure 2 shows the behaviour of $\alpha$ versus $\tau$ at $495.7 \mathrm{~nm}$ in the period July 2001-September 2003 for cloud-free conditions. A total of 1616 cloud-free measurements at the 5 values of solar zenith angle are reported in Fig. 2. The measurements derive from a total of 304 days. The summer, spring, and autumn-winter days represent, respectively, 54\%, 28\%, and $18 \%$ of the total number of days. It is worth mentioning that there are some gaps in the measurement record due the presence of clouds and, in minor part, to instrumental problems. The longest lasting interruption due to instrumental problems occurred in August 2002. Other interruptions occurred in October 2001, February 2002 and November 2002. The optical depth vs. Ångström exponent plot, and in general the combined use of these two parameters, allows the discrimination of different aerosol types. This method has been used in a large number of studies and is based on the sensitivity of $\tau$ and $\alpha$ to different, somewhat independent, microphysical aerosol properties: $\alpha$ depends (mainly) on size distribution and (less) on the refractive index, while $\tau$ depends mainly on the aerosol column density. Therefore, the $\tau-\alpha$ plot qualitatively indicates amount and dimension of the observed aerosol. Low and high values of $\alpha$ are due to the dominant presence of large and small particles, respectively, i.e. the preponderance of the coarse or the accumulation mode. The dependency of $\alpha$ on the size distribution has been widely used to distinguish among desert dust (e.g. Eck et al., 1999; Dubovik et al., 2002), urban-industrial (Eck et al., 1999; Smirnov et al., 2000; Dubovik et al., 2002; Kubilay et al., 2003), and biomass burning aerosols (Kaufman et al., 1998; Eck et al., 1999, 2001; Reid et al., 1999; Dubovik et al., 2002; Balis et al., 2003).

Two main groups of particles can be identified in Fig. 2: the first one includes data with large values of $\tau$ and low values of $\alpha$, typical of Saharan dust; the second one contains points with large values of both $\tau$ and $\alpha$, typical of urbanindustrial or biomass burning aerosols. The data point distribution of Fig. 2 is continuous, suggesting that other families of particles are present, as well as cases of mixing of different aerosol types.

Marine aerosols are expected to contribute significantly to the dataset as local component. Smirnov et al. (2002) describe photometric measurements at remote oceanic sites in clear marine background conditions, and obtain values of $\alpha$ between 0.3 and 0.7. As discussed by Smirnov et al. (2002), at remote marine sites the aerosol optical characteristics mostly depend on the geographical location, because of the advection of non-marine aerosol types; the influence of non marine particles is particularly important for inland seas.

In the following sections aerosol parameters at $\theta=60^{\circ}$ will be used together with airmass trajectories to identify sources and properties of particles originating from different geographical sectors.

\subsection{Identification of the aerosol origin}

Five-day back trajectories ending at Lampedusa are calculated by means of the Hysplit Dispersion Model (Draxler and Rolph, 2003) to identify the origin of the airmasses; the employed model version includes vertical wind. Each trajectory is associated with the corresponding aerosol optical properties. Relating column integrated quantities, such as $\tau$ and $\alpha$, to trajectories ending at specific altitudes may be problematic. Nevertheless, back trajectories are widely used in connection with aerosol optical depth (e.g. Formenti et al., 2001; Kubilay et al., 2003; Balis et al., 2003).

In this study we use trajectories that end over Lampedusa at 750, 2000, and $4000 \mathrm{~m}$. Previous investigations based on spring-summer lidar observations (di Sarra et al., 2001) and model results (e.g. Alpert et al., 2004) have shown that African airmasses are generally loaded with desert dust up to at least $4 \mathrm{~km}$, and often up to $7-8 \mathrm{~km}$. Conversely, when airmasses originate from other regions the aerosol is generally confined within the lowest $2-3 \mathrm{~km}$ of the atmosphere. In 
this study we assume that the trajectories that end at $4000 \mathrm{~m}$ provide information on the transport of desert dust, that generally travels over the mixed layer; the dust load is generally large, and dominant in the atmospheric column. We also assume that trajectories ending at $2000 \mathrm{~m}$ are useful to identify aerosols originating from Northern sectors, while the trajectory ending at $750 \mathrm{~m}$ are indicative of the circulation in the lowest troposphere. We define three broad geographical sectors, displayed in Fig. 3, in relation to different aerosol sources. The identified sectors are:

A) a Southern sector, coinciding with the African continent; the dominant source is the Sahara desert;

B) a Western sector, which includes the Atlantic Ocean, the Mediterranean Basin, the Iberian Peninsula and the Western France; in this region the prevalent sources produce marine and, to a lesser extent, continental aerosols;

C) a North, North-Eastern sector, which includes Central and Eastern Europe; anthropogenic sources are expected to be dominant in this sector.

A degree of arbitrariness in the definition of the sectors exists, due to the effective distribution of the sources. A different identification of the sectors is thus possible. Figure 3 shows 5-day trajectories ending at Lampedusa at $2000 \mathrm{~m}$. Two trajectories per day, corresponding to $\theta=60^{\circ}$, are displayed for the years 2002 and 2003, when measurements of $\tau$ are available (i.e. only in cloud-free conditions, and for slowly changing aerosol optical depth, see Sect. 2). The trajectory colours in Fig. 3 indicate the value of $\alpha$ measured at the final point. Low values of $\alpha$ are measured for airmasses coming from North Africa, while airmasses arriving from sectors $\mathrm{B}$ and $\mathrm{C}$ display progressively increasing Ångström exponents. A similar dependency was found in the Eastern Mediterranean by Formenti et al. (2001), who measured aerosol properties at Mount Athos (Greece) in JuneSeptember 1998. They found that the largest values of $\alpha$ correspond to airmasses coming from Eastern Europe and Russia.

The aerosol origin sector can be identified by considering the time spent in the different sectors along the trajectory (di Sarra et al., 2001; Gerasopoulos et al., 2003), or by more sophisticated correlation methodologies (Formenti et al., 2001). Previous results (di Sarra et al., 2001), as well as a preliminary analyses of this dataset, indicate that dust is loaded in the air column even after a marginal passage over the African continent. Therefore, the time spent in each sector does not always provide information on the aerosol origin.

For this reason, we developed a different method to identify the aerosol source sector. We assume that the aerosol is confined to the mixed layer at the source location, and we look for regions along the trajectory where the airmass interacts with the mixed layer. We assume that aerosol is
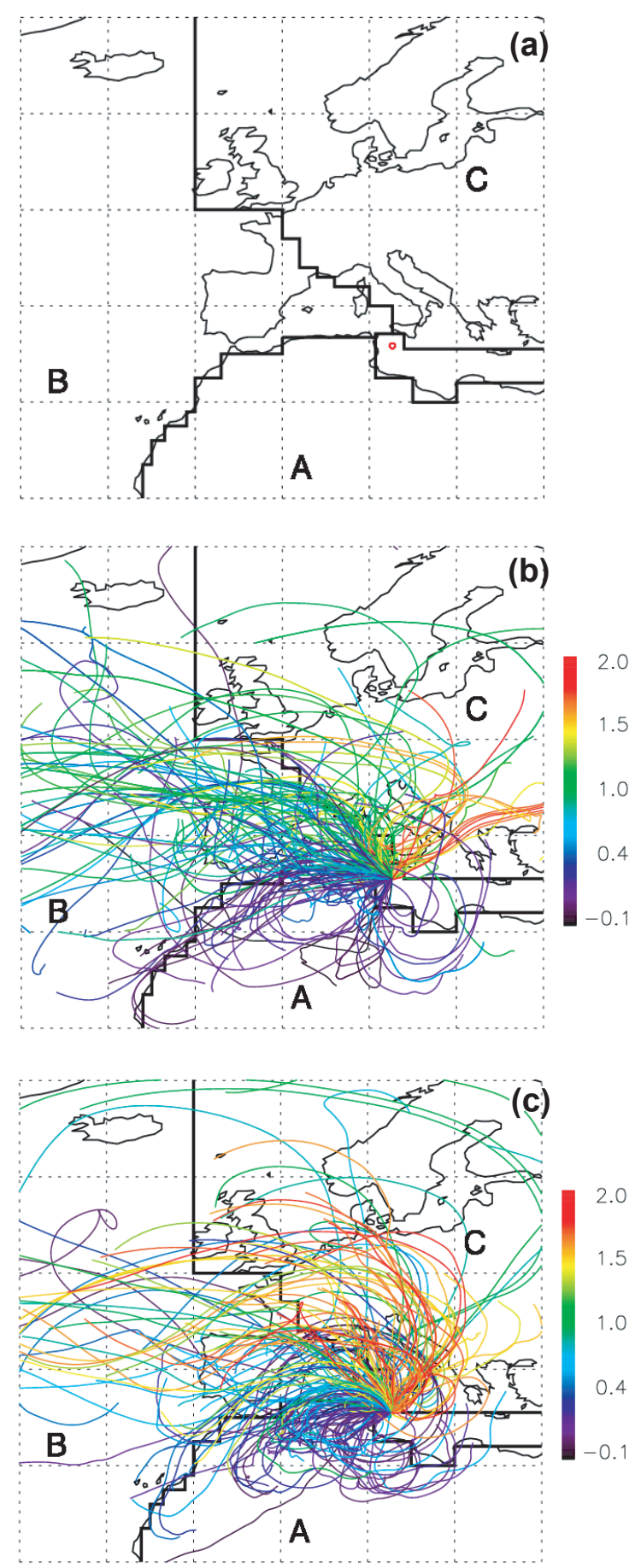

Fig. 3. Five-day trajectories ending at Lampedusa at $2000 \mathrm{~m}$, in (b) 2002, and (c) 2003. The colour of the trajectories refers to the corresponding value of $\alpha$ measured at Lampedusa. Two trajectories per day, corresponding to a solar zenith angle of $60^{\circ}$, are displayed. The different source regions are split into three sectors (A, B, and C) shown in panel (a). The position of Lampedusa is indicated by a red circle. 


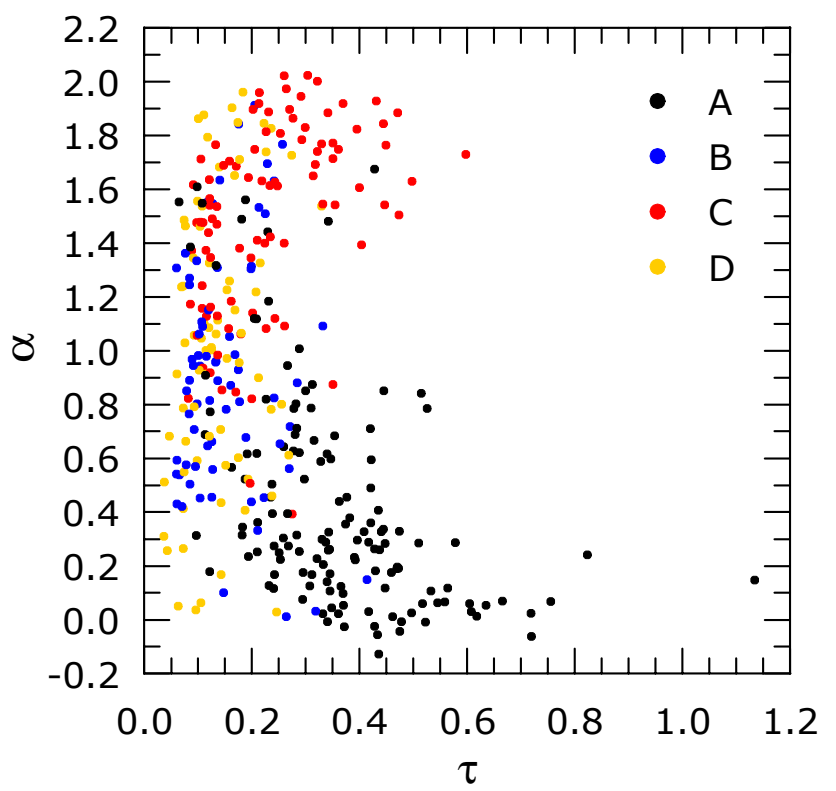

Fig. 4. Behaviour of the Ångström exponent, $\alpha$, as a function of the aerosol optical depth at $495.7 \mathrm{~nm}, \tau$. Only data corresponding to a solar zenith angle of $60^{\circ}$ are considered. The colour of the symbols indicates the airmass originating sector.

loaded when the airmass altitude, $\mathrm{z}_{\mathrm{air}}$, is lower or close to the altitude of the mixed layer, $\mathrm{z}_{\mathrm{mxl}}$; we apply the condition $\left(\mathrm{z}_{\mathrm{air}}-\mathrm{z}_{\mathrm{mxl}}\right)<500 \mathrm{~m}$ (entrainment condition). The mixed layer altitude is defined as in the Hysplit model, i.e. the height at which the potential temperature first exceeds the value at ground by $2 \mathrm{~K}$; a minimum value of $250 \mathrm{~m}$ is assumed. The geographical sector where this condition is met along the trajectory is identified as the source of the observed aerosol. A region of $1.5^{\circ}$ latitude $\times 1.5^{\circ}$ longitude centered at Lampedusa is excluded from the search. If the entrainment condition is met at more than one point, we choose the geographical position where the difference $\left(\mathrm{z}_{\mathrm{air}}-\mathrm{Z}_{\mathrm{mxl}}\right)$ is lowest (sign included). Both the airmass and mixed layer altitudes are supplied by the Hysplit dispersion model.

We check first if the entrainment condition is satisfied along the trajectory ending at $4000 \mathrm{~m}$; if this is not the case, the trajectory ending at $2000 \mathrm{~m}$ is checked. The entrainment condition for trajectories ending at $4000 \mathrm{~m}$ is satisfied only by African airmasses. It is interesting that all airmasses of African origin satisfy the entrainment condition for trajectories ending either at 2000 or at $4000 \mathrm{~m}$. In fact, the mixed layer altitude is much larger over the African sector than over sectors $\mathrm{B}$ and $\mathrm{C}$. The average and standard deviation of $\mathrm{Z}_{\mathrm{mxl}}$ over all the trajectories for the three sectors are $1404 \pm 1314 \mathrm{~m}$ for sector $\mathrm{A}, 523 \pm 310 \mathrm{~m}$ for B, and $537 \pm 324 \mathrm{~m}$ for $\mathrm{C}$.

If the entrainment condition is never met during the 5-day trajectory, we consider the time spent by the airmasses in each sector (permanence condition). The time spent in a $1.5^{\circ}$ latitude and longitude square around the island is excluded from the calculations. We classify an airmass as originating from sectors $\mathrm{C}$ or $\mathrm{B}$ when it spent more than $50 \%$ and $75 \%$ of the last 5 days in the respective sector. The two different thresholds are determined empirically to take into account different mixed layer properties. The airmasses which do not satisfy any of those criteria are classified as of undetermined origin (D).

\subsection{Back trajectories and aerosol optical properties}

In this section the aerosol optical properties are related to the identified originating sectors. For this analysis we use aerosol parameters at $\theta=60^{\circ}$, for a total of 365 trajectories. Figure 4 shows the behaviour of $\alpha$ versus $\tau$ for the 365 selected data; different symbols indicate measurements classified as originating from sector A, B, C, or undetermined (D).

Average values of $\tau$ and $\alpha$ for the different sectors, and the number and frequency of occurrence of trajectories classified in each sector, are reported in Table 1.

We tested the main assumptions adopted in the backtrajectories analysis by considering different length of the trajectories, and modifying the boundary between sectors B and $\mathrm{C}$.

The influence of the trajectory length was examined by classifying all the airmasses using 3-day and 7-day trajectories. The results, expressed as percent change from those derived with 5-day trajectories, are reported in Table 2. Note that Table 2 includes also results obtained modifying the sector boundaries, as will be discussed below. The use of 3-day or 7-day trajectories does not significantly modify the average optical properties of each class. The smallest number of cases classified as undetermined occur for 5-day trajectories.

The choice of the 3 geographical sectors is based on the possibility to identify dominant sources of a determined aerosol type over broad geographical regions. In this respect the definition of sectors $\mathrm{A}$ and $\mathrm{C}$ is constrained by the available information on the distribution of sources, respectively desert dust and anthropic sources. The largest degree of arbitrariness is the choice of the borders between sectors B and C. In our study we adopted a conservative solution for the identification of anthropic aerosols, excluding Spain and Western France from sector $\mathrm{C}$. The sensitivity of the results to the choice of the boundaries between sectors B and $\mathrm{C}$ has been tested by extending sector $\mathrm{C}$ to include France and the Pyrenees. The results are reported in last column of Table 2. As expected, the number of sector $\mathrm{C}$ cases increases $(+4.3 \%)$, as well as that of undetermined origin $(+14.1 \%)$, while the sector B cases decrease. There is no change for the African cases. The average aerosol optical properties of the different sectors show little variations. Thus, the simple trajectory classification scheme appears sufficiently robust to allow the identification of broad classes of aerosol properties.

As a conclusion of the sensitivity study, we believe that the proposed classification is robust enough to allow the identification of main classes of aerosol properties. 
Table 1. Mean, standard deviation and number of occurrences (frequency) of $\tau$ and $\alpha$, for airmasses originating from different sectors. Data are averaged around the solar zenith angle of $60^{\circ}$.

\begin{tabular}{ccccc}
\hline Sector & Whole period & Autumn-winter & Spring & Summer \\
\hline Number of occurrences & 365 & $42(11.5 \%)$ & $90(24.6 \%)$ & $233(63.8 \%)$ \\
\hline A (Northern Africa) & & & \\
\hline Number of occurrences & $132(36 \%)$ & $10(23 \%)$ & $24(26 \%)$ & $98(42 \%)$ \\
$\tau$ & $0.36 \pm 0.16$ & $0.25 \pm 0.14$ & $0.30 \pm 0.16$ & $0.38 \pm 0.16$ \\
$\alpha$ & $0.42 \pm 0.40$ & $0.50 \pm 0.46$ & $0.39 \pm 0.38$ & $0.42 \pm 0.40$ \\
\hline B (Atlantic - Western Europe) & & & \\
\hline Number of occurrences & $69(19 \%)$ & $15(35 \%)$ & $24(26 \%)$ & $30(13 \%)$ \\
$\tau$ & $0.15 \pm 0.08$ & $0.15 \pm 0.10$ & $0.12 \pm 0.04$ & $0.18 \pm 0.07$ \\
$\alpha$ & $0.92 \pm 0.44$ & $0.62 \pm 0.38$ & $0.80 \pm 0.29$ & $1.16 \pm 0.43$ \\
\hline C (Central - Eastern Europe) & & & \\
\hline Number of occurrences & $92(25 \%)$ & $4(10 \%)$ & $14(15 \%)$ & $74(31 \%)$ \\
$\tau$ & $0.23 \pm 0.11$ & $0.11 \pm 0.02$ & $0.19 \pm 0.06$ & $0.25 \pm 0.12$ \\
$\alpha$ & $1.50 \pm 0.36$ & $0.95 \pm 0.09$ & $1.06 \pm 0.14$ & $1.60 \pm 0.30$ \\
\hline$\alpha$ & & & & \\
\hline D (Undetermined) & & & & \\
\hline Number of occurrences & $72(20 \%)$ & $13(30 \%)$ & $28(31 \%)$ & $31(13 \%)$ \\
& $0.14 \pm 0.06$ & $0.12 \pm 0.08$ & $0.12 \pm 0.05$ & $0.20 \pm 0.06$ \\
\hline & $1.02 \pm 0.52$ & $0.51 \pm 0.34$ & $0.85 \pm 0.38$ & $1.39 \pm 0.43$ \\
\hline
\end{tabular}

The distribution of the number of occurrences of $\alpha$ and $\tau$ is shown in Fig. 5 for each of the 4 sectors, and for different seasons. Gaussian curves are fitted to the data and drawn in the figure. The distributions of the values of $\alpha$ for sectors B and D largely overlap those for sectors A and C, which are conversely quite well separated. The aerosol optical depth progressively decreases from sector $\mathrm{A}$, to $\mathrm{C}$, to $\mathrm{B} / \mathrm{D}$; values belonging to the different classes largely overlap. The range of values of both $\tau$ and $\alpha$ for sectors B and D are very similar.

The seasonal behaviour of $\tau$ is characterized by a distinct summer increase. The value of $\alpha$ increases in summer for all sectors, except for sector A. The Ångström exponent is largest for sector $\mathrm{C}$ and smallest for sector $\mathrm{A}$, indicating that the particles of sector $\mathrm{C}$ are smaller than those of sector $\mathrm{A}$; particles of sector A are the largest. The Ångström exponent increase from winter to summer for sectors B and C, and for class D suggests that the optical depth increment is mainly associated with an enhancement in the small particles' amount. This is probably due to the increased residence time of the aerosols, mostly affecting the accumulation mode, and to the increased efficiency of small size aerosol sources, like fires and photochemical smog. On the other hand, the weak seasonal change of $\alpha$ for sector A suggests that the summer optical depth increase is due to an enhancement in the total number of particles, and a limited increase in large particles.
About $36 \%$ of the airmasses belongs to sector A; $25 \%$ belongs to sector $\mathrm{C}, 19 \%$ to sector $\mathrm{B}$, and $20 \%$ to sector D. Airmasses from sectors $\mathrm{A}$ and $\mathrm{C}$ are more frequent in summer, when the occurrence of trajectories from NorthWest decreases. This distribution is essentially produced by the yearly evolution of the meteorological synoptic patterns over the Central Mediterranean, with strongest NorthWestern flows in winter, and largest Southern influence in summer. The aerosol seasonal cycle is well explained by the synoptic patterns and by the seasonal evolution of the aerosol production mechanisms and residence time.

The desert dust and biomass burning urban-industrial particles are well identified from the trajectory analysis, and correspond respectively to classes A and C. As expected, aerosols from sector A have the largest average aerosol optical depth, and the lowest Ångström exponent. The values of $\alpha$ of class A particles agree with those measured at Capo Verde for Saharan dust and oceanic particles (Dubovik et al., 2002). It is interesting that dust particles measured in the Arabic peninsula, in the Persian Gulf, or in the Hawaii display a larger range of values for $\alpha$ (Dubovik et al., 2002).

Sector B particles have relatively small optical depth (ranging from 0.11 to 0.19 ) and $\alpha$ between 0.5 and 1.2 ; these values are consistent with those of maritime particles mixed with anthropogenic aerosol or desert dust, as expected for an inland sea like the Mediterranean (Smirnov et al., 2002). 


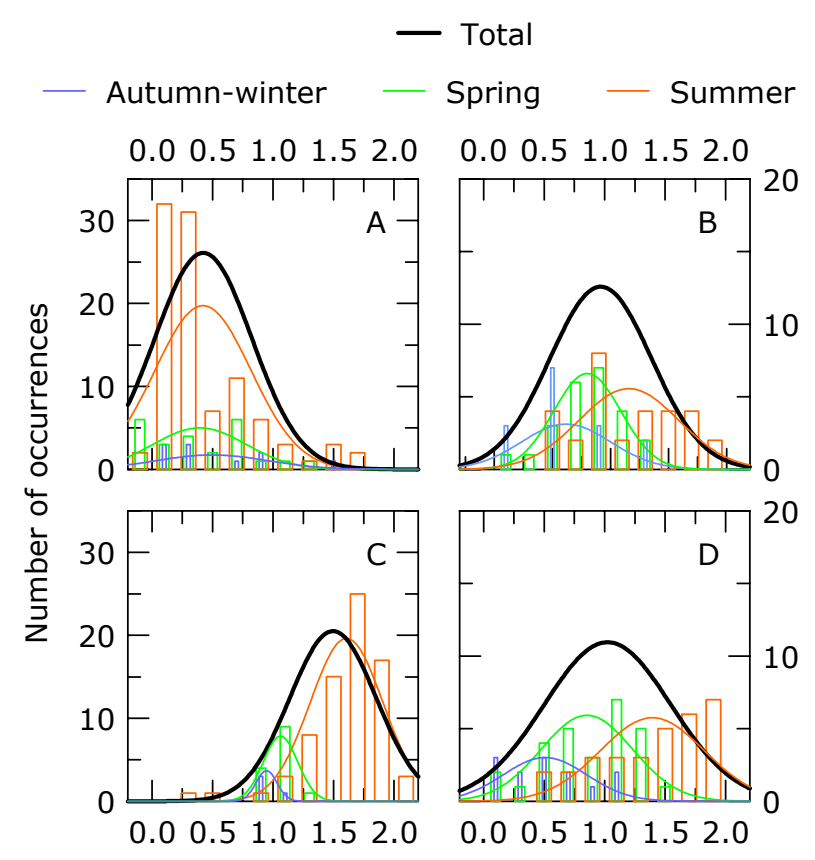

(a) $\alpha$

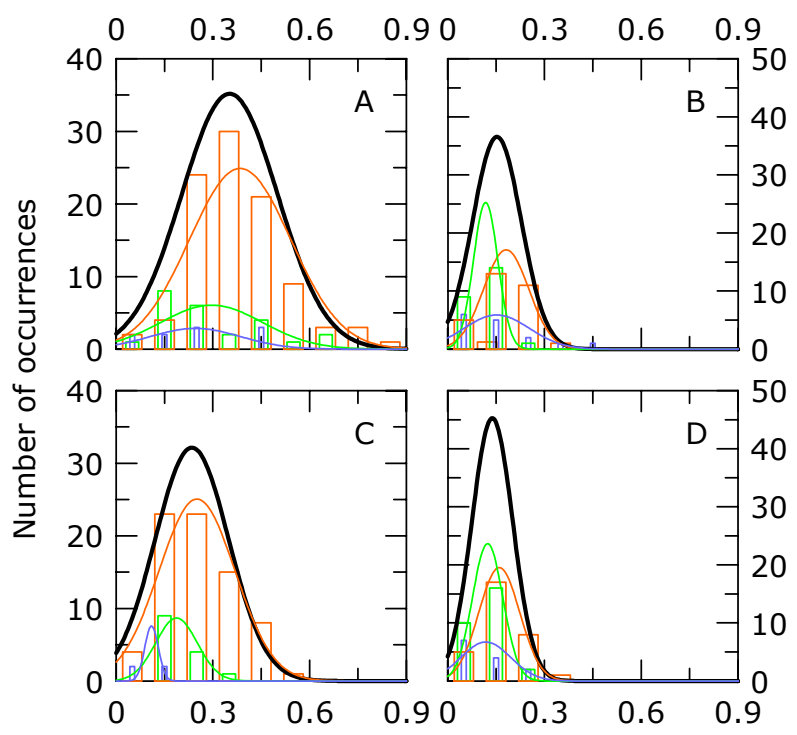

(b) $\tau$

Fig. 5. Distribution of the number of occurrences of (a) $\alpha$, and (b) $\tau$, for each of the 4 sectors: A, B, C, D. The seasonal data are shown in orange (Summer), green (Spring) and blue (AutumnWinter). Distributions for the different seasons (coloured lines) and for the whole dataset (black thick line) are identified by Gaussian curves fitted to the data.

As previously discussed, the ocean is considered the dominant aerosol source of the Western sector; however, this sector includes the Iberian Peninsula and Western France, and a non-homogeneous origin of the aerosol particles is expected. An additional analysis aimed at isolating the contribution

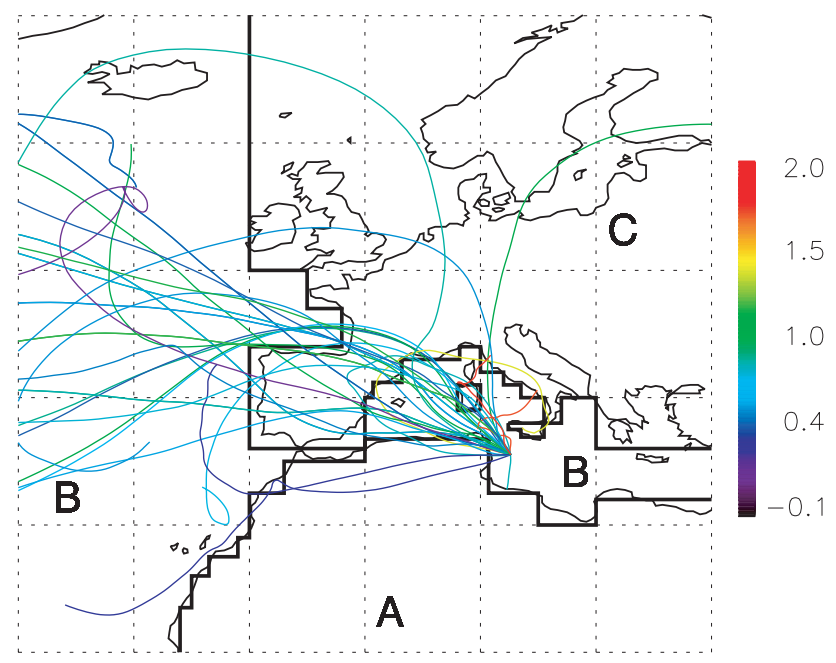

Fig. 6. Five-day trajectories ending at Lampedusa at $2000 \mathrm{~m}$ satisfying the criteria for marine cases, with at least $75 \%$ of the time spent over the sea. The colour of the curves indicates the value of $\alpha$ measured at Lampedusa at the end of the trajectory.

from marine aerosol has been carried out, and is discussed in Sect. 3.4.

The properties of aerosol from sector $\mathrm{C}$ correspond to urban-industrial and biomass burning particles, as identified by Dubovik et al. (2002). The largest values of $\alpha$ are observed during summer; as will be shown below, about $1 / 3$ of these cases is related to forest fires occurring in Europe during the warmest and driest months of 2003. The remaining data of sector $\mathrm{C}$ occur in autumn-winter and spring, and display properties similar to those of sectors B and D.

It must be emphasized that different aerosol types may be present in the air column at the same time, influencing the observed optical parameters. For example, there are isolated data points belonging to sector A with a value of $\alpha$ as large as 1.65 . As will be discussed in the following section, some of these cases are due to biomass burning products, that can not be captured by a simple trajectory analysis that does not take into account the location of fires. Similarly, there are data points classified as C with $\alpha=0.4$, or classified as B with large optical depth and low Ångström exponent.

An interesting example of mixing has been discussed by Eck et al. (1999). They show a case with values of $\alpha$ and $\tau$ at $500 \mathrm{~nm}$ respectively of 1 and 0.43 , resulting from the mixing of desert and industrial aerosols; the mixing led to a size distribution having accumulation and coarse mode of similar amplitude.

We examined all the trajectories that produce outliers in the data distribution of each specific sector to verify the coherence between the classification based on the airmass trajectories and the aerosol optical parameters. Most of the outliers correspond to relatively fast changes of the airmass path occurring within about one day. These changes determine a 
Table 2. Percent variations in the number of occurrences and average values of $\tau$ and $\alpha$ obtained using 3-day, 7-day backward trajectories, and different boundary between sectors $\mathrm{B}$ and $\mathrm{C}$, with respect to the data of Table 1.

\begin{tabular}{cccc}
\hline Sector & 3 days & 7 days & Different B, C boundary \\
\hline A (Northern Africa) & & & \\
\hline Number of occurrences & $-5.0 \%$ & $+9.3 \%$ & $0.0 \%$ \\
$\tau$ & $0.0 \%$ & $-2.7 \%$ & $0.0 \%$ \\
$\alpha$ & $-7.0 \%$ & $+14.0 \%$ & $0.0 \%$ \\
\hline B (Atlantic - Western Europe) & & \\
\hline Number of occurrences & $-1.4 \%$ & $+5.6 \%$ & $-19.4 \%$ \\
$\tau$ & $+6.6 \%$ & $0.0 \%$ & $-6.7 \%$ \\
$\alpha$ & $-8.0 \%$ & $+3.3 \%$ & $-7.6 \%$ \\
\hline C (Central - Eastern Europe) & & $+4.3 \%$ \\
\hline Number of occurrences & $+6.0 \%$ & $-25.8 \%$ & $0.0 \%$ \\
$\tau$ & $0.0 \%$ & $+8.7 \%$ & $0.0 \%$ \\
$\alpha$ & $-2.7 \%$ & $+1.3 \%$ & \\
\hline D (Undetermined) & & & $0.0 \%$ \\
\hline Number of occurrences & $+2.7 \%$ & $+11.2 \%$ & $1.0 \%$ \\
$\alpha$ & $0.0 \%$ & $-7.1 \%$ &
\end{tabular}

weakening of the relation between the trajectory and the optical characteristics; a large uncertainty on the trajectory path or on the estimate of the mixing layer altitude, a large variability of the aerosol properties, and/or a large inhomogeneity of the aerosol vertical distribution, are among the possible causes.

In Sect. 3.5 we discuss the summer 2003 observations, when unusual meteorological conditions influenced the aerosol load over the Central Mediterranean basin. In this period desert dust and biomass burning particles are clearly identifiable. Mixed aerosol types are also observed; they correspond to many of the outliers of Fig. 4.

\subsection{Identification of marine aerosol}

The identification of cases of clean marine aerosols is particularly complex in the Mediterranean, due to the influence of the surrounding continents and the limited dimension of the basin. For example, Prospero et al. (1979) collected aerosol samples over different oceans and report that all Mediterranean samples were heavily contaminated by dust and anthropic pollutants. Smirnov et al. (1995) discuss measurements of aerosol optical depth in the Atlantic Ocean and Mediterranean Sea. They consider the Mediterranean as a "coastal" region. They pointed out that significant difference between coastal and oceanic regions in the values of $\alpha$ exist, and classified the Mediterranean observations in 3 classes: "standard atmosphere" $(0.2<\tau<0.3$ and $0.7<\alpha<1.6)$, Saharan outflows $(0.6<\tau<0.7$ and $0.6<\alpha<0.8)$, and "pure at- mosphere" $(0.04<\tau<0.06)$. More recently, Heintzenberg et al. (2000) reviewed the size distribution and chemical composition of marine aerosols. They excluded from the analysis the Baltic, the Mediterranean and the Sea of Japan, considered not representative for clean marine conditions.

Thus, although marine aerosol is expected to contribute significantly to the optical properties of the arimasses classified as sector $\mathrm{B}$, additional analyses are required to isolate clean marine cases. The analyses are based on the identification of the effective time that the trajectory spent over the ocean, and the occurrence of a strong interaction with the marine mixed layer.

To this purpose, we adopted a more detailed mask of the European continent, defining a large oceanic sector that includes the Atlantic ocean and the Mediterranean (see Fig. 6). Then, we excluded the trajectories ending at 4000 or $2000 \mathrm{~m}$ that satisfy the entrainment condition in sectors $\mathrm{A}$ and $\mathrm{C}$, and those that satisfy the permanence condition in sector $\mathrm{C}$. The no-search zone around Lampedusa was eliminated.

An air mass is considered representative of the marine environment when:

1. the entrainment condition is met in the Mediterranean part of the oceanic sector at 4000 or $2000 \mathrm{~m}$.

2. both trajectories arriving at Lampedusa at 750 and $2000 \mathrm{~m}$ spent more than a given fraction of the last five days over the ocean. 
Table 3. Mean and standard deviation values of $\tau$ and $\alpha$ for the marine cases selected with different thresholds on the fraction of time spent over the sea along the trajectories at 750 and $2000 \mathrm{~m}$.

\begin{tabular}{cccc}
\hline $\begin{array}{c}\text { Persistence } \\
\text { threshold }\end{array}$ & $\tau$ & $\alpha$ & $\begin{array}{c}\text { Number } \\
\text { of cases }\end{array}$ \\
\hline$>65 \%$ & $0.12 \pm 0.05$ & $0.89 \pm 0.44$ & 42 \\
$>75 \%$ & $0.11 \pm 0.04$ & $0.86 \pm 0.41$ & 29 \\
$>85 \%$ & $0.10 \pm 0.03$ & $0.81 \pm 0.49$ & 11 \\
\hline
\end{tabular}

Figure 6 shows the selected trajectories arriving at Lampedusa at $2000 \mathrm{~m}$ with a $75 \%$ threshold on the fraction of time spent over the sea. The colour of the trajectory indicates the measured value of the Ångström exponent. Table 3 shows the average values of $\tau$ and $\alpha$, and the number of cases that meet the adopted criteria for at least $65 \%, 75 \%$, and $85 \%$ of the last 5-day spent over the sea. The value of the threshold appears to impact the results, with progressively decreasing average optical depth and Ångström exponent; the number of cases that satisfy the selection criteria also decreases rapidly for increasing threshold. The average values of $\alpha$ and $\tau$ agree with those obtained at remote islands in the Atlantic Ocean (Ascention and Bermuda), as discussed by Smirnov et al. (2002). They point out that Ascention and Bermuda are influenced by transport of different types of aerosol from continents, and show "mixed maritime" aerosol characteristics; in particular, they show higher values of $\tau(\sim 0.13)$ than at remote sites in the Pacific Ocean, like Lanai, Nauru, Tahiti, and higher variability of $\alpha$. The average columnar optical properties we obtain are expected to represent cases of dominant marine background. However, cases of mixed aerosols may still be present among the selected data.

A further examination of the selected trajectories shows that values of $\tau<0.12$ correspond to a progressively decreasing altitude of the airmass along the trajectory; conversely, values of $\tau>0.12$ are associated with a higher variability in the flight altitude. Descending airmasses are expected to have a small interaction with the continental surface, and produce low values of the aerosol optical depth by transporting clean mid tropospheric air to lower altitudes. Furthermore, air masses of north-western origin are frequently associated to relatively intense winds at low altitude, thus leading to an increase in the marine aerosol load in the mixed layer. In these cases the aerosol content is possibly dominated by marine particles. Thus, it appears that marine aerosols play a dominant role only when other types of particles are absent.

\subsection{Case study: July-August 2003}

Figure 7 shows the mean values of $\tau$ and $\alpha$ at different solar zenith angles during the period 28 June (day 179)-1 September (day 244) 2003. Different symbols indicate the identified

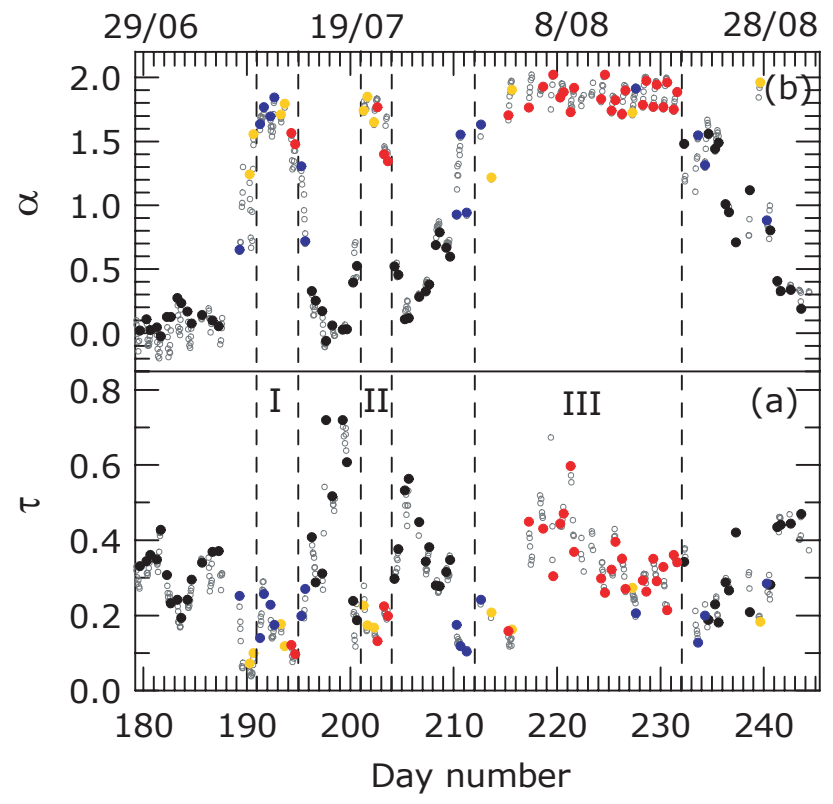

Fig. 7. Behaviour of a) $\tau$ at $495.7 \mathrm{~nm}$, and b) $\alpha$ (values at $60^{\circ}$ solar zenith angle are indicated by solid circles in black, blue, red, and orange; open grey circles indicate values at other solar zenith angles) in the period 28 June-1 September 2003. The colours of the solid circles identify the origin of the airmass according to the trajectory analysis (see Fig. 4).

airmass origin at $\theta=60^{\circ}$. Three intervals with $\alpha \geq 1.5$ (periods I, II, and III) are highlighted in the figure. Values of $\tau$ are generally $>0.2$ during July and August, and are $\geq 0.4$ around days 181, 196-198, 204-205, 218-225, and 243245; $\alpha$ varies from -0.2 to +2 . The longest period with persistent large values of $\alpha$ lasts from day 212 to 232 , when $\tau$ is generally $>0.3$; these data belong to class $\mathrm{C}$, and are unusual in the whole dataset. It is thus worth investigating their possible causes.

Summer 2003 has been the European hottest summer since 1500 (Luterbacher et al., 2004). A persistent high pressure system remained centred over Western Europe during most of July and August, contributing to maintain high temperatures and dry weather. These conditions were favourable to the enhancement in the atmospheric aerosol concentration, and to the development of forest fires: huge, ravaging and persistent fires developed in Portugal, Provence, Italy, and the Balkan region; such fires and their plumes are well documented in satellite images (see e.g. http://visibleearth.nasa. gov). The exceptionally high temperature, as well as the increase in the ambient ozone and aerosol concentration led to a number of deaths higher than normal (e.g. Fisher et al., 2004; Stedman, 2004).

Large amounts of biomass burning particles were driven from the European continent to the Central-Southern Mediterranean by the high pressure system. Eck et al. $(1999,2001)$ have shown that biomass burning aerosol is 
characterized by large values of $\alpha$, generally $>1.5$. Biomass burning aerosol in Brazil, Zambia, and Canada were observed to produce mean values of $\tau$ at $440 \mathrm{~nm}$ between 0.4 and 0.8 , and values of $\alpha$ in the range from 1.2 to 2.2 (Dubovik et al., 2002). Recently Balis et al. (2003) reported observations of smoke plumes originating from different European regions (Southern Italy, Danube region and Northern Black Sea). They measured instantaneous values of $\tau$ as large as 0.84 at $440 \mathrm{~nm}$, and values of $\alpha$ between 1.78 and 1.82 in August 2001 at Thessaloniki (Greece). Urban/industrial aerosols display large values of $\alpha$ : generally $\alpha>1.4$ in Southern Europe (Holben et al., 2001; Gerasopoulos et al., 2003).

To identify sources of biomass burning particles we use the Web Fire Mapping that provides daily maps of fires (http://maps.geog.umd.edu/default.asp, a collaboration between NASA Goddard Space Flight Center and University of Maryland based on the MODerate resolution Imaging Spectroradiometer, MODIS, data). The daily maps are combined with the airmass trajectories. Figure 8 shows 5-day trajectories ending at Lampedusa at $2000 \mathrm{~m}$ in the period 28 June-1 September 2003. The colour code indicates the value of $\alpha$.

Observations of the period I are discussed in the companion paper by Meloni et al. (2005), and we focus here on periods II and III. In period II the trajectories at all altitude levels overpass Sicily and Southern Italy, where several fires were active during the previous days. In period III almost all airmasses flowed over Sicily, where fires were active, before approaching Lampedusa. During the previous days trajectories overpassed different regions with forest fires: the East Adriatic coast, South-Eastern Italy, Sardinia, and the Northern coast of Africa. Thus, we attribute the values of $\alpha \geq 1.5$ to biomass burning particles; urban sources may constitute an additional, although not dominant, contribution. To our knowledge, fire plume episodes of such a large temporal and spatial extension have not been previously reported in the Mediterranean.

Meloni at al. (2005) show that the retrieved aerosol single scattering albedo of periods II and III corresponds to biomass burning, coherently with our finding. Their analysis also shows that biomass burning or urban/industrial particles are dominant in the aerosol column on different days.

Before and after each of the three periods, Saharan dust outbreaks lead to rapid changes of the aerosol characteristics. In the transition periods, particles displaying intermediate/mixed optical properties appear. In particular, at the beginning of period III (days 208-210) airmasses are classified as A; the observed value of $\alpha$ is between 0.5 and 0.8 , and $\tau$ is about 0.3 . Such a large value of $\tau$ is usually connected to dust or heavily polluted/fire particles; however, the corresponding value of $\alpha$ does not allow to discriminate between the two aerosol types. MODIS satellite images show a large desert haze over the sea, West and North-West of Sardinia and Corsica, and a large smoke plume from fires over Central Corsica on 22 July (day 203). According to the trajectories, the airmass arriving at Lampedusa at $2000 \mathrm{~m}$ on 27 July

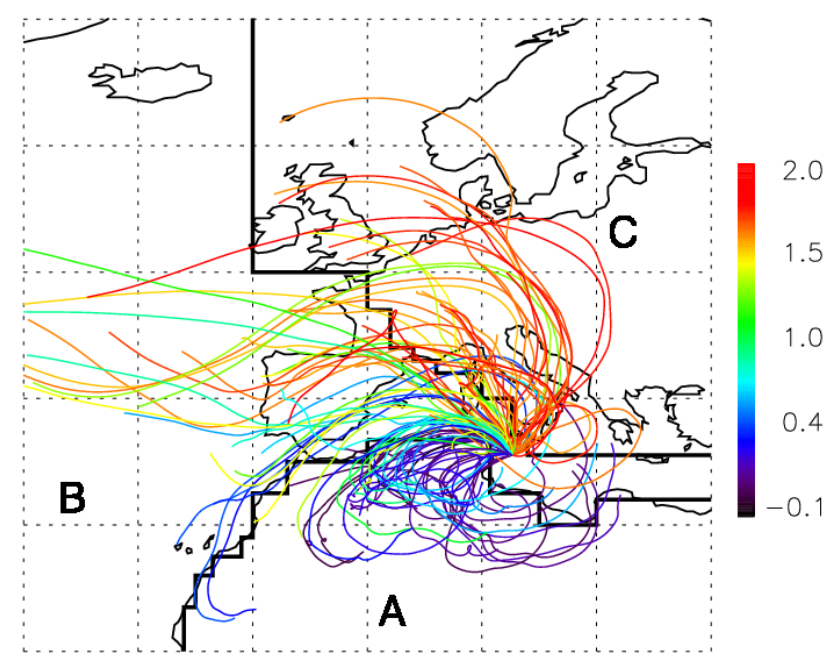

Fig. 8. Five-day trajectories ending at Lampedusa at $2000 \mathrm{~m}$ in the period 28 June-1 September 2003. Two trajectories per day corresponding to values of the solar zenith angle of $60^{\circ}$ are displayed, except in cloudy periods. The colour of the curves indicates the value of $\alpha$ measured at Lampedusa at the end of the trajectory.

(day 208), loaded with desert dust, captured smoke particles overpassing Corsica on 22 July. Thus, the observed optical parameters (daily average $\tau=0.28$ and $\alpha=0.81$ ) are the result of mixing of different aerosol types. Similar cases are also documented by satellite imagery. The Web Fire Mapping also shows frequent fires along the Northern coast of Africa in August 2003; their presence probably explains the cases of particles classified as A displaying $\alpha \sim 0.75$ and $\tau>0.2$.

\section{Column load and aerosol types}

In this section the observed values of $\tau$ and $\alpha$ (mean values at fixed solar zenith angles, $\theta=20^{\circ}, 30^{\circ}, 40^{\circ}, 50^{\circ}, 60^{\circ}$ ) are studied with respect to the typical optical properties of desert dust and biomass burning-urban/industrial aerosol types, hereafter indicated as DD and BU, respectively. These two classes of particles produce significantly different radiative effects: in the visible spectral range scattering is prevalent for $\mathrm{DD}$, and absorption for BU particles. Thus, the identification of cases with a single dominant aerosol type is essential for the assessment of the aerosol radiative effects in the Mediterranean. The companion paper by Meloni at al. (2005) is dedicated to the determination of the aerosol single scattering albedo; their analysis is based on the following classification of the main aerosol types.

As discussed above, there is rarely a single aerosol type in the air column over the Mediterranean, since marine particles are usually dominant in the mixed layer, and other types mix and/or travel above. However, we identify cases dominated by a single type when the values of $\tau$ and $\alpha$ are within specific conservative ranges; these ranges are defined 


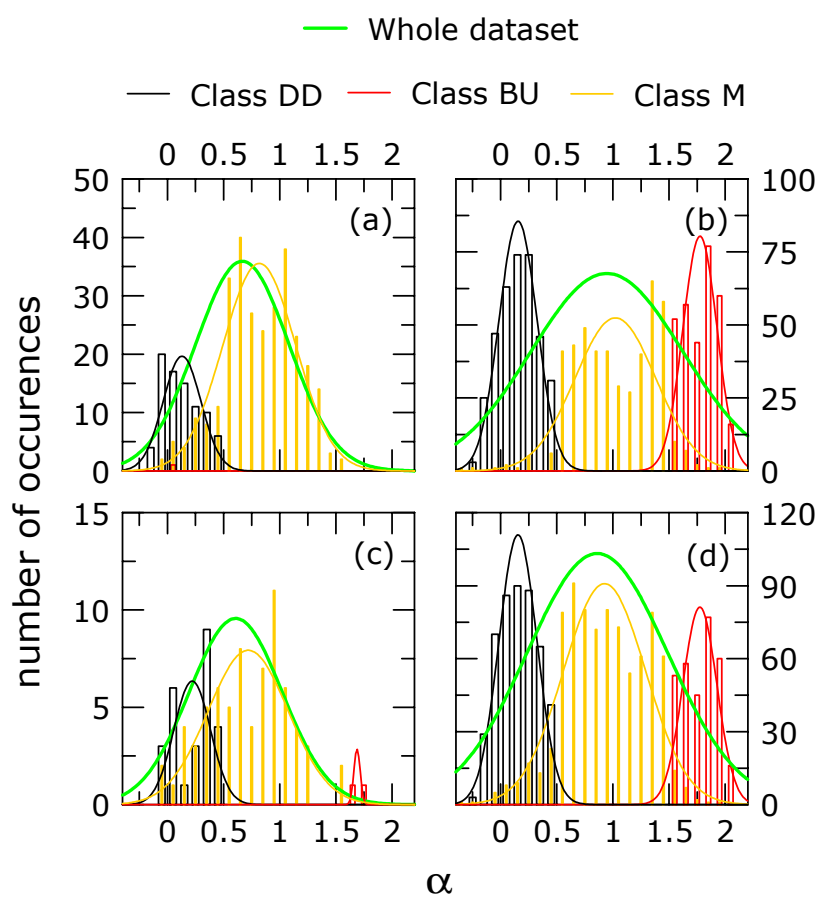

Fig. 9. Spring (a), summer (b), autumn-winter (c), and the whole dataset (d), distribution of the number of occurrences of $\alpha$. Histograms and Gaussian curves fitted to the data for the DD, BU and $\mathrm{M}$ classes are indicated by black, red, and yellow lines respectively. Green tick lines indicate Gaussian curves fitted to the whole dataset.

using typical values for desert dust and biomass burningurban/industrial aerosol derived from the literature (see the discussion in Sect. 3.3), and the distribution of the observed values of $\tau$ and $\alpha$ at Lampedusa (see Fig. 4). We assume that cases dominated by DD are those with $\tau \geq 0.15$ and $\alpha \leq 0.5$; cases dominated by BU particles are those with $\tau \geq 0.1$ and $\alpha \geq 1$.5. The properties of marine particles have been discussed in Sect. 3.4. Although other types might be identified, it would not be possible to distinguish cases dominated by a single type from cases of mixed aerosol. Thus, for this analysis, we define only two aerosol types, and classify the remaining cases as mixed (M). Class $\mathrm{M}$ contains also the clean marine conditions discussed in Sect. 3.4.

It is worth emphasizing that about $90 \%$ of the class DD data originates from sector A, $6 \%$ to sector B, and only 1 and $3 \%$ to sector $\mathrm{C}$ and class $\mathrm{D}$, respectively. Conversely, $65 \%$ of the $\mathrm{BU}$ data originates from sector $\mathrm{C}, 13 \%$ from sector $\mathrm{B}$ and $2 \%$ from sector A, while $20 \%$ belongs to class D. As expected, DD particles have a more defined geographical origin, and frequently produce conditions dominated by a single aerosol type. The reader is reminded that these statistics are derived from trajectories ending at Lampedusa at $\theta=60^{\circ}$.

Figures 9 and 10 display the number of occurrences of $\alpha$ and $\tau$ for DD, BU, and $\mathrm{M}$ aerosol types for the whole dataset and in different seasons. Three summer data points

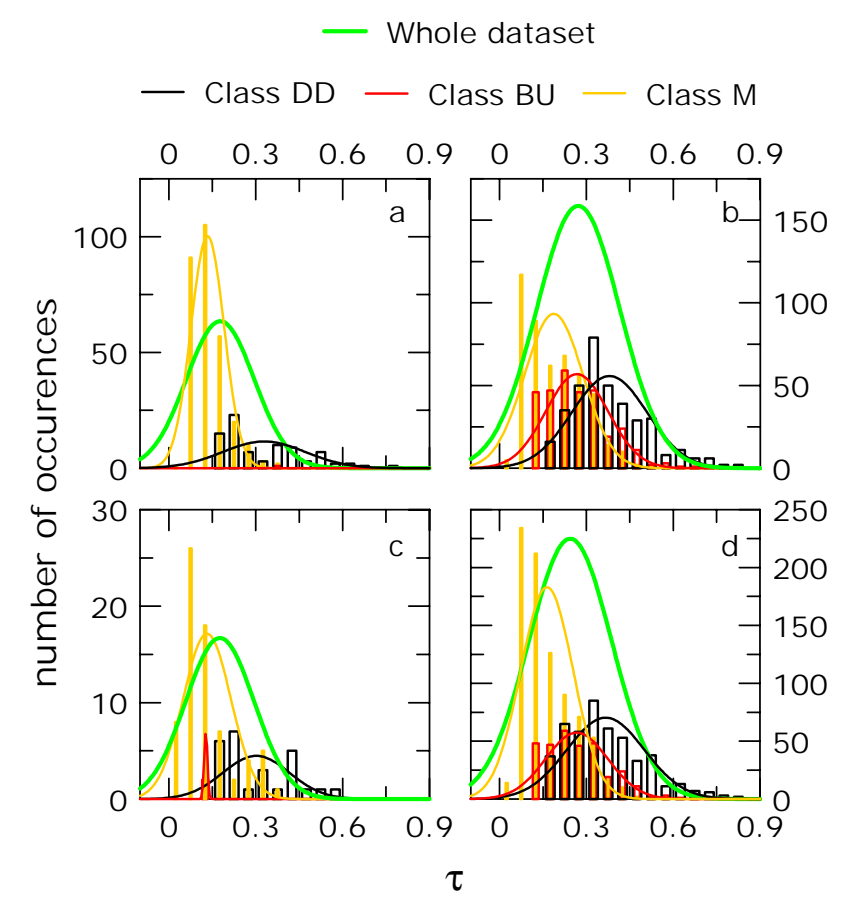

Fig. 10. Same as Fig. 8, but for $\tau$.

with $\tau>0.9$ are excluded from Figs. 9 and 10 to increase the readability of the histograms. Due to the annual variability of cloudiness, the amount of available data is not uniform throughout the year, and the statistical significance of the results is larger in spring and summer. Autumn and winter data together constitute only $6.1 \%$ of the dataset, and are grouped together. Table 4 reports number, frequency of occurrence, mean, and standard deviation of the distribution of $\tau$ and $\alpha$.

The overall mean and standard deviation of $\tau$ and $\alpha$ are $0.24 \pm 0.14$ and $0.86 \pm 0.63$, respectively. The values of $\tau$ range from 0.03 to 1.13 , while the values of $\alpha$ vary from -0.32 to 2.05 . The average values of $\tau$ and $\alpha$ are influenced by the uneven temporal distribution of data, and their significance must be considered with caution. For this reason we calculated three different averages, whose results are reported in Table 5: the first is calculated over the whole dataset; the second is calculated over two entire annual cycles; the third is calculated from daily averages, using all the available cloud-free periods, and over two entire annual cycles. The third average value is smaller than the other two, that contain a larger number of observations at solar zenith angles $<60^{\circ}$ during spring and summer.

Gerasopoulos et al. (2003) discuss observations of aerosol properties at a rural (Ouranoupolis $40.4^{\circ} \mathrm{N}, 23.9^{\circ} \mathrm{E}$ ) and an urban site (Thessaloniki, $40.6^{\circ} \mathrm{N}, 22.9^{\circ} \mathrm{E}$ ) in Northern Greece. They report averages of aerosol optical depth at $500 \mathrm{~nm}: \tau=0.23 \pm 0.13$ at the rural site, and $0.23 \pm 0.15$ at the urban site; their results are very close to those obtained in this study. It has to be noted that the averages are calculated by 
Table 4. Mean, standard deviation and number (frequency) of occurrences of $\tau$ and $\alpha$, for the identified aerosol types. Data are averaged around $20^{\circ}, 30^{\circ}, 40^{\circ}, 50^{\circ}$, and $60^{\circ}$ solar zenith angle.

\begin{tabular}{|c|c|c|c|c|}
\hline Aerosol type & Whole period & Autumn-winter & Spring & Summer \\
\hline \multicolumn{5}{|l|}{ Whole dataset } \\
\hline Number of occurrences & 1616 & $99(6 \%)$ & $373(23 \%)$ & $1144(71 \%)$ \\
\hline$\tau$ & $0.24 \pm 0.14$ & $0.18 \pm 0.12$ & $0.18 \pm 0.18$ & $0.27 \pm 0.14$ \\
\hline$\alpha$ & $0.86 \pm 0.63$ & $0.61 \pm 0.41$ & $0.67 \pm 0.42$ & $0.95 \pm 0.68$ \\
\hline \multicolumn{5}{|l|}{ DD (Desert dust) } \\
\hline Number of occurrences & $475(30 \%)$ & $26(26 \%)$ & $83(23 \%)$ & $366(32 \%)$ \\
\hline$\tau$ & $0.37 \pm 0.14$ & $0.30 \pm 0.12$ & $0.33 \pm 0.14$ & $0.39 \pm 0.14$ \\
\hline$\alpha$ & $0.15 \pm 0.17$ & $0.22 \pm 0.16$ & $0.13 \pm 0.17$ & $0.16 \pm 0.17$ \\
\hline \multicolumn{5}{|c|}{ BU (Biomass burning / urban-industrial) } \\
\hline Number of occurrences & $309(19 \%)$ & $2(2 \%)$ & $1(0.03 \%)$ & $306(27 \%)$ \\
\hline$\tau$ & $0.27 \pm 0.11$ & $0.13 \pm 0.01$ & $0.31 \pm 0.01$ & $0.27 \pm 0.11$ \\
\hline$\alpha$ & $1.77 \pm 0.15$ & $1.69 \pm 0.03$ & $1.55 \pm 0.05$ & $1.78 \pm 0.15$ \\
\hline \multicolumn{5}{|l|}{ M (Mixed) } \\
\hline Number of occurrences & $832(51 \%)$ & $71(72 \%)$ & $289(77 \%)$ & $472(41 \%)$ \\
\hline$\tau$ & $0.16 \pm 0.09$ & $0.13 \pm 0.09$ & $0.13 \pm 0.06$ & $0.19 \pm 0.10$ \\
\hline$\alpha$ & $0.93 \pm 0.37$ & $0.72 \pm 0.36$ & $0.82 \pm 0.32$ & $1.02 \pm 0.34$ \\
\hline
\end{tabular}

Table 5. Mean and standard deviation of $\tau$ and $\alpha$ calculated with different data selection criteria.

\begin{tabular}{cccc}
\hline $\begin{array}{c}\text { Period } \\
\text { Type of data }\end{array}$ & $\begin{array}{c}\text { July 2001-Sep 2003 } \\
\text { Whole dataset }\end{array}$ & $\begin{array}{c}\text { Aug 2001-Aug 2003 } \\
\text { Whole dataset }\end{array}$ & $\begin{array}{c}\text { Aug 2001-Aug 2003 } \\
\text { Daily means }\end{array}$ \\
\hline$\tau$ & $0.24 \pm 0.14$ & $0.23 \pm 0.14$ & $0.22 \pm 0.13$ \\
$\alpha$ & $0.86 \pm 0.63$ & $0.87 \pm 0.64$ & $0.82 \pm 0.59$ \\
\hline
\end{tabular}

Gerasopoulos et al. (2003) over the entire datasets, and may differ from annual means. Average values of $\alpha$ are much larger $(1.4 \pm 0.4$ and $1.6 \pm 0.3$ at the rural and urban site, respectively) than at Lampedusa. This difference is attributed to the different geographical locations and the corresponding prevalent aerosol types. Northern Greece is strongly influenced by regional (anthropic) sources, and occasionally experiences cases of long range transport of desert dust. Conversely, the geographic position of Lampedusa determines a dominant role of long-range transport, and, due to the proximity of Africa, a stronger influence from desert dust.

The distribution of the values of $\alpha$ for class $M$ shows a bimodal behaviour. The first peak at smaller values of $\alpha$ can be associated to the prevalence of marine aerosols, as discussed in Sect. 3.4.

As it is evident in Fig. 10, the optical depth seasonal evolution of all aerosol types is characterized by a summer increase. The presence of aerosol classified as BU is a distinct summer phenomenon, since very few cases occur in autumn-winter, and no cases in spring. Desert dust is known to display a clear seasonal cycle in the central Mediterranean (Moulin et al., 1998; Israelevich et al., 2002), with a distinct summer maximum. The increase in the optical depth of the other aerosol types is related to the stronger convection, and the longer permanence of particles in the atmosphere during summer. Gröbner and Meleti (2004) report observations of aerosol optical depth at $443 \mathrm{~nm}$ at Ispra (Italy) during the period 1995-2002; their data show a distinct annual cycle, with a maximum of 0.5 in June, and a minimum (0.18) in November-December. Multiyear measurements with MFRSR radiometers in Central and Eastern US show a summer increase in $\tau$ and $\alpha$, followed by a reduction in autumn-winter; the annual average $\alpha$ is close to 1.3, representative of continental aerosols (Michalsky et al., 2001). They show that the seasonal cycle is larger in the Eastern coast than in the rest of US. The seasonal behaviour in the US is confirmed by other climatological studies (Holben et al., 2001; Alexandrov et al., 2002). Holben et al. (2001) extend this result to all Northern midlatitude continental sites. 
The summer increase in $\tau$ and $\alpha$ at Lampedusa is consistent with other Sun photometric measurements at Southern Europe sites. Observations at Ispra (Italy, $45.8^{\circ} \mathrm{N}$, $\left.8.6^{\circ} \mathrm{E}\right)$ during $1997-1998$ show a monthly mean maximum of $\tau=0.52$ at $500 \mathrm{~nm}$ in June, and two maxima of $\alpha$ (calculated between 440 and $870 \mathrm{~nm})$ in May and July (1.62 \pm 0.15 and 1.61 \pm 0.13 ) (Holben et al., 2001). Monthly mean values of $\alpha$ measured at Tito Scalo (Italy, $40.6^{\circ} \mathrm{N}, 15.72^{\circ} \mathrm{E}$ ) decrease from $1.73 \pm 0.25$ in June, to $0.90 \pm 0.03$ in October 2001, confirming the reduction in the content of small particles from summer to fall (Esposito et al., 2004). Cachorro et al. (2000) discuss data acquired from March to November 1995 at a rural station in the north central Spain. They show an increase of $\tau$ during the summer month, with a maximum monthly mean of $\tau \sim 0.33$ in June. Gerasopoulos et al. (2003) show that maxima of $\tau$ and $\alpha$ monthly averages occur in August ( $\sim 0.3$ and $\sim 1.6$, respectively), and minima in December $(\sim 0.09$ and $\sim 1.0$, respectively) at a rural site in Northern Greece. They find a different behaviour at the Greek urban site, where no clear annual cycle appears; monthly values of $\alpha$ are generally large (ranging from $\sim 1.3$ to $\sim 1.7$ ), possibly due to the influence of local pollution.

We can not exclude that part of the seasonality observed at Lampedusa is induced by the temporal distribution of cloudiness. However, the behaviour of the urban-industrial and biomass burning aerosol is essentially determined by the accumulation mode, and observations reflect the longer residence time, the stronger efficiency of sources (mainly for forest fires), and the stronger convective regime occurring in summer. Entrainment of aerosol particles in the free troposphere, allowing for long range transport, may also play a role. Entrainment in the free troposphere is stronger in the convective regimes characteristic of the summer season in Central-Southern Europe, while it is normally reduced in the temperature inversion regime typical of colder months.

The increased capability of the summer advection regime to transport aerosols of European origin to the Mediterranean is discussed by Stohl et al. (2002) and Duncan and Bey (2004), who show that the main outflow toward the Mediterranean Basin and Africa occurs during summer; this flow is strongly reduced during the other seasons.

Multi-year aerosol optical depth estimates were derived from satellite observations. The retrieval of the optical depth from satellite data depends on some assumptions. Due to these assumptions and to the interannual variability of the aerosol distribution (e.g. Moulin et al., 1997a), a direct comparison is problematic. However, satellite data are available over extended time periods, and a comparison of our results with these climatological values may provide useful indications.

Using 11 years of Meteosat data Moulin et al. (1998) estimate the African dust seasonal contribution to the aerosol optical depth over the Central Mediterranean; they retrieve a seasonal average dust optical depth at $550 \mathrm{~nm}$ of $0.08 \pm 0.02$, $0.15 \pm 0.06,0.18 \pm 0.06,0.09 \pm 0.04$, respectively for winter, spring, summer, and autumn; the annual mean is $0.13 \pm 0.04$. The aerosol optical depth at $550 \mathrm{~nm}$ is calculated from the MFRSR observations at Lampedusa using the Ångström law. Averaging daily values, we obtain an annual mean of $0.20 \pm 0.13$, and seasonal averages of $0.15 \pm 0.11,0.16 \pm 0.11$ and $0.25 \pm 0.13$ for autumn-winter, spring and summer, respectively. Our dataset refers to a different and shorter time period, and the comparison should be considered with caution. However, we measure substantially larger values of $\tau$, and a less pronounced dust seasonal cycle. This difference can be due to the South to North decrease of the average desert dust optical depth in the Mediterranean (Barnaba and Gobbi, 2004). An underestimate of the aerosol optical depth in the Meteosat retrieval (Moulin et al., 1997b) may also contribute.

Husar et al. (1997) derived monthly average aerosol optical depths from AVHRR (Advanced Very High Resolution Radiometer) observations at $630 \mathrm{~nm}$ the for the period July 1989-June 1991. They obtain an annual mean of 0.18 in the Mediterranean basin; the annual aerosol optical depth cycle has a minimum of about 0.07 in December, and a maximum of about 0.28 in August. Averaging their monthly aerosol optical depths we derive values of about $0.11,0.23$, and 0.26 for autumn-winter, spring and summer, respectively. Our measurements of $\tau$ at $615 \mathrm{~nm}$ give an annual mean of $0.19 \pm 0.13$, and values of $0.14 \pm 0.11,0.15 \pm 0.11$ and $0.23 \pm 0.13$ for autumn-winter, spring and summer, respectively. The annual averages are very similar, but we observe a less pronounced annual cycle, with larger values of $\tau$ during autumn-winter, and lower during spring and summer. It must be pointed out that the results by Husar et al. (1997) are integrated over the whole basin, and significant differences in the aerosol seasonal behaviour in the various parts of the Mediterranean exist (see e.g. Moulin 1998; Israelevich 2002).

\section{Conclusions}

At the island of Lampedusa ENEA maintains a Station for Climate Observations, where measurements of greenhouse gases, aerosol properties, total ozone, ultraviolet and solar radiation and other climatic parameters are carried out. Lampedusa is a small island located in the Central Mediterranean, East of Tunisia and South of Sicily, without significant local aerosol sources. In this study we present almost 2.5 years of aerosol optical depth and Ångström exponent measurements obtained with a multi filter rotating shadowband radiometer (MFRSR).

The main results of this analysis may be summarized as follows:

1. The average aerosol optical depth at $495.7 \mathrm{~nm}$ and the average Angström exponent are $0.24 \pm 0.14$ and $0.86 \pm 0.63$, respectively, over the period July 2001September 2003. The observed values of $\tau$ range from 
0.03 to 1.13 , and the values of $\alpha$ vary from -0.32 to 2.05 , indicating a large variability in aerosol content and size.

2. The airmasses were classified according to the originating sectors during the cloud-free periods. $36 \%$ of the airmasses come from Africa, 25\% from CentralEastern Europe, and 19\% from Western France, Spain and the North Atlantic. In summer, $42 \%$ of the airmasses is of African origin. In almost all cases African aerosols display high values of $\tau$ and low values of $\alpha$, typical of Saharan dust (average values of $\tau$ and $\alpha$ are 0.36 and 0.42 , respectively). Particles originating from Central-Eastern Europe show relatively large average values of $\tau$ and $\alpha$ ( 0.23 and 1.5 , respectively), while particles from Western France, Spain and the North Atlantic show the lowest average values of $\tau(0.15)$, and relatively small values of $\alpha(0.92)$.

3. Clean marine aerosol conditions are rare at Lampedusa. They are mostly related to specific meteorological conditions that determine the absence of aerosol transported by the Europe and Africa that, if present, largely affect the column aerosol properties. Clean marine columnar aerosol display low values of $\tau$ (generally between 0.07 and 0.11 ), and an average value of $\alpha$ of $\sim 0.8$.

4. Cases of intermediate values of $\alpha$ are often related to relatively fast changes in the airmass originating sector, suggesting the contemporary presence of different types of particles in the air column. The largest values of $\alpha$ (about 2) are observed in August 2003, when intense forest fires in Southern Europe produced large amounts of fine combustion particles, that were transported to the Central Mediterranean by a persistent high pressure system over Central Europe. Smoke particles in some cases mix with desert dust, producing intermediate values of $\alpha$.

5. The seasonal distribution of the meteorological patterns over the Mediterranean, the efficiency of the aerosol production mechanisms, and the variability of the particles' residence time in the atmosphere produce a distinct seasonal cycle of aerosol optical depths and Ångström exponent values. Particles originating from all sectors show a summer maximum in aerosol optical depth. The summer increase in optical depth for European aerosols is linked with an increment in the values of $\alpha$, that indicates an enhancement in the number of fine particles. The summer maximum of $\tau$ for African particles is associated with a weak reduction in the Angström exponent, suggesting an increase in the total number of particles and a relatively more intense transport of large particles.

6. The observations were classified according to the aerosol optical properties, and two main classes have been identified: desert dust (DD) and biomass burning/urban-industrial (BU) aerosols. Values of $\tau$ and $\alpha$ averaged over the whole observing period are 0.37 and 0.15 for DD, and 0.27 and 1.77 for BU. $90 \%$ of the cases classified as DD originate from Africa, while $65 \%$ of the BU cases originate from Central-Eastern Europe. A seasonal evolution of the aerosol properties of the different types is also evident.

Acknowledgements. We acknowledge the NOAA Air Resources Laboratory (ARL) for provision of the HYSPLIT transport and dispersion model, and of the READY website (http://www.arl.noaa. gov/ready.html), whose results are used in this publication. We appreciate the provision of data via internet by the science teams of TOMS and of Web Fire Mapping. This work has been partially supported by the Ministry for Environment of Italy.

The reviewers' suggestions helped to improve the significance of the paper. Their contribution is acknowledged.

Edited by: W. Conant

\section{References}

Alexandrov, M. D., Lacis, A. A., Carlson, B., and Cairns, B.: Remote sensing of atmospheric and trace gases by means of multifilter rotating shadowband radiometer. Part II: Climatological applications, J. Atmos. Sci., 59, 544-566, 2002.

Alpert, P., Kishcha, P., Shtivelman, A., Krichak, S. O., and Joseph, J. H.: Vertical distribution of Saharan dust based on 2.5-year model predictions, Atmos. Res., 70, 109-130, 2004.

Balis, D. S., Amiridis, V., Zerefos, C., Gerasopoulos, E., Andreae, M., Zanis, P., Kazadzis, A., and Papayannis, A.: Raman lidar and sunphotometric measurements of aerosol optical properties over Thessaloniki, Greece during a biomass burning episode, Atmos. Environ., 37, 4529-4538, 2003.

Barnaba, F. and Gobbi, G. P.: Aerosol seasonal variability over the Mediterranean region and relative impact of maritime, continental and Saharan dust particles over the basin from MODIS data in the year 2001, Atmos. Chem. Phys., 4, 2367-2391, 2004.

Bogumil, K., Orphal, J., Homann, T., Voigt, S., Spiet, P., Fleischmann, O. C., Vogel, A., Hartmann, M., Kromminga, H., Bovensmann, H., Frerick, J., and Burrows, J. B.: Measurements of molecular absorption spectra with the SCIAMACHY pre-flight model: instrument characterization and reference data for atmospheric remote-sensing in the $230-2380 \mathrm{~nm}$ region, J. Photochem. Photobiol. A, 157(2-3), 167-184, 2003.

Bolle, H.-J.: Climate, climate variability, and impacts in the Mediterranean area: an overview, in: Mediterranean Climate: Variability and Trends, edited by: Bolle, H.-J., Springer-Verlag, 5-86, 2003.

Cachorro, V. E., Durán, P., Vergaz, R., and de Frutos, A. M.: Measurements of the atmospheric turbidity of the north-centre continental area in Spain: spectral aerosol optical depth and Ångström turbidity parameters, J. Aerosol Sci., 31, 687-702, 2000.

Chamard, P., Thiery, F., di Sarra, A., Ciattaglia, L., De Silvestri, L., Grigioni, P., Monteleone, F., and Piacentino, S.: Interannual variability of atmospheric $\mathrm{CO}_{2}$ in the Mediterranean: Measurements at the island of Lampedusa, Tellus, 55B, 83-93, 2003. 
di Sarra, A., Di Iorio, T., Cacciani, M., Fiocco, G., and Fuà, D.: Saharan dust profiles measured by lidar from Lampedusa, J. Geophys. Res., 106, 10 335-10 347, 2001.

di Sarra, A., Cacciani, M., Chamard, P., Cornwall, C., DeLuisi, J. J., Di Iorio, T., Disterhoft, P., Fiocco, G., Fuà, D., and Monteleone, F.: Effects of desert dust and ozone on the ultraviolet irradiance at the Mediterranean island of Lampedusa during PAUR II, J. Geophys. Res., 107(D18), 8135, doi:10.1029/2000JD000139, 2002.

di Sarra, A., Cacciani, M., DeLuisi, J., De Silvestri, L., Di Iorio, T., Fiocco, G., and Grigioni, P.: Desert aerosol in the Mediterranean, in: Mediterranean Climate: Variability and Trends, edited by: Bolle, H.-J., Springer-Verlag, 309-315, 2003.

Draxler, R. R. and Rolph, G. D.: HYSPLIT (Hybrid Single-Particle Lagrangian Integrated Trajectory) model, http://www.arl.noaa. gov/ready/hysplit4.html, NOAA Air Resour. Lab., Silver Spring, MD, 2003.

Dulac, F., Tanré, D., Bergametti, G., Buat-Méenard, P., Desbois, M., and Sutton, D.: Assessment of the African airborne dust mass over the Western Mediterranean sea using Meteosat data, J. Geophys. Res., 97, 2489-2506, 1992.

Duncan, B. N. and Bey I.: A modelling study of the export pathways of pollution from Europe: Seasonal and interannual variation (1987-1997), J. Geophys. Res., 109, D08301, doi:10.1029/2003JD004079, 2004.

Dubovik, O., Holben, B. N., Eck, T. F., Smirnov, A., Kaufman, Y. J., King, M. D., Tanré, D., and Slutsker, I.: Variability of absorption and optical properties of key aerosol types observed in worldwide locations, J. Atmos. Sci., 59, 590-608, 2002.

Eck, T. F., Holben, B. N., Reid, J. S., Dubovik, O., Smirnov, A., O'Neill, N. T., Slutsker, I., and Kinne, S.: Wavelength dependence of optical depth of biomass burning, urban, and desert dust aerosols, J. Geophys. Res., 104, 31 333-31 349, 1999.

Eck, T. F., Holben, B. N., Ward, D. E., Dubovik, O., Reid, J. S., Smirnov, A., Mukelabai, M. M., Hsu, N. C., O’Neill, N. T., and Slutsker, I: Characterisation of the optical properties of biomass burning aerosols in Zambia during the 1977 ZIBBEE fiels campaign, J. Geophys. Res., 106, 3425-3448, 2001.

Esposito F., Leone, L., Pavese, G., Restieri, R., and Serio, C.: Seasonal variation of aerosol properties in South Italy: a study on aerosol optical depths, Ångström turbidity parameters and aerosol size distributions, Atmos. Environ., 38, 1605-1614, 2004.

Fisher, P. H., Brunekreef, B., and Lebret, E.: Air pollution related deaths during 2003 heat wave in the Netherlands, Atmos. Environ., 38, 1083-1085, 2004.

Formenti, P., Andreae, M. O., Andreae, T. W., Galani, E., Vasaras, A., Zerefos, C., Amiridis, V., Orlovsky, L., Karnieli, A., Wendisch, M., Wex, H., Holben, B. N., Maenhaut, W., and Lelieveld, J.: Aerosol optical properties and large-scale transport of air masses: Observations at a coastal and a semiarid site in the eastern Mediterranean during summer 1998, J. Geophys. Res. 106(D9), 9807-9826, 2001.

Gerasopoulos, E., Andreae, M. O., Zerefos, C. S., Andreae, T. W., Balis, D., Formenti, P., Merlet, P., Amiridis, V., and Papastefanou, C.: Climatological aspects of aerosol optical properties in Northern Greece, Atmos. Chem. Phys., 3, 2025-2041, 2003.

Gröbner, J. and Meleti, C.: Aerosol optical depth in the UVB and visible wavelength range from Brewer spectrophotometer direct irradiance measurements: 1991-2002, J. Geophys. Res., 109,
D09202, doi:10.1029/2003JD004409, 2004.

Hansen, J. E. and Travis, L. D.: Light scattering in planetary atmospheres, Space Sci. Rev., 16, 257-610, 1974.

Harrison, L., Michalsky, J., and Berndt, J.: Automated multifilter rotating shadowband radiometer: an instrument for optical depth and radiation measurements, Appl. Opt., 33, 5118-5125, 1994.

Harrison, L. and Michalsky, J.: Objective algorithms for the retrieval of optical depths from ground-based measurements, Appl. Opt., 33, 5126-5132, 1994.

Heintzenberg, J., Covert, D. C., and Van Dingenen, R.: Size distribution and chemical composition of marine aerosols: a compilation and review, Tellus, 52B, 1104-1122, 2000.

Holben, B. N., Tanré, D., Smirnov, A., et al.: An emerging ground-based aerosol climatology: Aerosol optical depth from AERONET, J. Geophys. Res., 106(D11), 12 067-12 098, 2001.

Horvath, H., Arboledas, L. A., Olmo, F. J., Jovanovic, O., Gangl, M., Kaller, W., Sanchez, C., Sauerzopf, H., and Seidl, S.: Optical characteristics of the aerosol in Spain and Austria and its effect on radiative forcing, J. Geophys. Res., 107(D19), 4386, doi:10.1029/2001JD001472, 2002.

Husar, R. B., Prospero, J. M., and Stowe, L. L.: Characterization of tropospheric aerosols over the oceans with the NOAA advanced very high resolution radiometer optical thickness operational product, J. Geophys. Res., 102(D14), 16 889-16909, 1997.

Israelevich, P. L., Levin, Z., Joseph, J. H., and Ganor, E.: Desert aerosol transport in the Mediterranean region as inferred from the TOMS aerosol index, J. Geophys. Res., 107(D21), 4572, doi:10.1029/2001JD002011, 2002.

Israelevich, P. L., Ganor, E., Levin, Z., and Joseph, J. H.: Annual variations of physical properties of desert dust over Israel, J. Geophys. Res., 108(D13), 4381, doi:10.1029/2002JD003163, 2003.

Jamet, C., Moulin, C., and Thiria, S.: Monitoring aerosol optical properties over the Mediterranean from SeaWiFS images using a neural network inversion, Geophys. Res. Lett., 31, L13107, doi:10.1029/2004GL019951, 2004.

Kaufman, Y. J., Hobbs, P. V., Kirchoff, W. J. H., et al.: Smoke, Clouds and Radiation-Brazil (SCAR-B) experiment, J. Geophys. Res., 103, 31 783-31 808, 1998.

Kubilay, N., Cokacar, T., and Oguz, T.: Optical properties of mineral dust outbreaks over the northeastern Mediterranean, J. Geophys. Res., 108(D21), 4666, doi:10.1029/2003JD003798, 2003.

Lelieveld, J., Berresheim, H., Borrmann, S., et al.: Global air pollution crossroads over the Mediterranean, Science, 298, 794-799, 2002.

Levin, Z., Ganor, E., and Gladstein, V.: The effects of desert particles coated with sulfate on rain formation in the Eastern Mediterranean, J. Appl. Meteorol., 35, 1511-1523, 1996.

Luterbacher, J., Dietrich, D., Xoplaki, E., Grosjean, M., and Wanner, H.: European seasonal and annual temperature variability, trends, and extremes since 1500, Science, 303, 1499-1503, 2004.

Markowicz, K. M., Flatau, P. J., Ramana, M. V., Crutzen, P. J., and Ramanathan, V.: Absorbing mediterranean aerosols lead to a large reduction in the solar radiation at the surface, Geophys. Res. Lett., 29, 1968, doi:10.1029/2002GL015767, 2002.

Meloni, D., di Sarra, A., DeLuisi, J., Di Iorio, T., Fiocco, G., Junkermann, W., and Pace, G.: Tropospheric aerosols in the Mediterranean: II. Radiative effects through model simulations and measurements, J. Geophys. Res., 108(D10), 4317, 
doi:10.1029/2002JD002807, 2003a.

Meloni, D., di Sarra, A., Fiocco, G., and Junkermann, W.: Tropospheric aerosols in the Mediterranean: III. Measurements and modeling of actinic radiation profiles, J. Geophys. Res., 108(D10), 4323, doi:10.1029/2002JD003293, 2003b.

Meloni, D., di Sarra, A., Di Iorio, T., and Fiocco, G.: Direct radiative forcing of Saharan dust in the Mediterranean from measurements at Lampedusa island and MISR spaceborne observations, J. Geophys. Res., 109(D8), D08206, doi:10.1029/2003JD003960, 2004.

Meloni, D., di Sarra, A., Pace, G., and Monteleone, F.: Optical properties of aerosol over the Central Mediterranean. 2. Determination of single scattering albedo at two wavelengths for different aerosol types, Atmos. Chem. Phys., 6, 715-727, 2006.

Michalsky, J. J., Schlemmer, J. A., Berkheiser, W. E., Berndt, J. L., Harrison, L. C., Laulainen, N. S., Larson, N. R., and Barnard, J. C.: Multiyear measurements of aerosol optical depth in the Atmospheric Radiation Measurement and Quantitative Links program, J. Geophys. Res., 106(D11), 12 099-12 107, 2001.

Moulin, C., Lambert, C. E., Dulac, F., and Dayan, U.: Control of atmospheric export of dust from North Africa by the North Atlantic oscillation, Nature, 387, 691-694, 1997a.

Moulin, C., Dulac, F., Lambert, C. E., Chazette, P., Jankowiak, I., Chatenet, B., and Lavenu, F.: Long-term daily monitoring of Saharan dust load over ocean using Meteosat ISCCP-B2 data: 1. Accuracy of the method and validation using Sun photometer measurements, J. Geophys. Res., 102, 16 959-16969, 1997 b.

Moulin, C., Lambert, C. E., Dayan, U., Masson, V., Ramonet, M., Bousquet, P., Legrand, M., Balkanski, Y. J., Guelle, W., Marticorena, B., Bergametti, G., and Dulac, F.: Satellite climatology of African dust transport in the Mediterranean atmosphere, J. Geophys. Res., 103, 13 137-13 144, 1998.

Prospero, J. M.: Mineral and sea salt aerosol concentration in various ocean regions, J. Geophys. Res., 84, 725-731, 1979.
Reid, J. S., Eck, T. F., Christopher, S. A., Hobbs, P. V., and Holben, B. N.: Use of the Angstrom exponent to estimate the variability of optical and physical properties of aging smoke particles in Brazil, J. Geophys. Res., 104, 27 473-27 489, 1999.

Sabbah, I., Ichoku, C., Kaufman, Y. J., and Remer, L.: Full year cycle of desert dust spectral optical thickness and precipitable water vapor over Alexandria, Egypt, J. Geophys. Res., 106, 18305 18316, 2001.

Smirnov, A., Yershov, O., and Villevalde, Y.: Measurement of aerosol optical depth in the Atlantic Ocean and the Mediterranean Sea, SPIE, 2582, 203-214, 1995.

Smirnov, A., Holben, B. N., Dubovik, O., O’Neill, N. T., Remer, L. A., Eck, T. F., Slutsker, I., and Savoie, D.: Measurement of atmospheric optical parameters on U.S. Atlantic coast sites, ships, and Bermuda during TARFOX, J. Geophys. Res., 105, 98879901, 2000.

Smirnov, A., Holben, B. N., Kaufman, Y. J., Dubovik, O., Eck, T. F., Slutsker, I., Pietras, C., and Halthore, R. N.: Optical properties of atmospheric aerosol in maritime environments, J. Atmos. Sci., 59, 501-523, 2002.

Stedman, J. R.: The predicted number of air pollution related deaths in the UK during the August 2003 heatwave, Atmos. Environ., 38, 1087-1090, 2004.

Stohl, A., Eckhardt, S., Forster, C., James, P., and Spichtinger, N.: On the pathways and timescales of intercontinental air pollution transport, J. Geophys. Res., 107(D23), 4684, doi:10.1029/2001JD001396, 2002.

Tanré, D., Kaufman, Y. J., Holben, B. N., Chatenet, B., Karnieli, A., Lavenu, F., Blarel, L., Dubovik, O., Remer, L. A., and Smirnov, A.: Climatology of dust aerosol size distribution and optical properties derived from remotely sensed data in the solar spectrum, J. Geophys. Res., 106, 18 205-18 217, 2001. 